\title{
Microplasma: A New Generation of Technology for Functional Nanomaterial Synthesis
}

\author{
Liangliang Lin ${ }^{1} \cdot$ Qi Wang ${ }^{1}$
}

Received: 31 March 2015/Accepted: 13 July 2015/Published online: 15 August 2015

(C) The Author(s) 2015. This article is published with open access at Springerlink.com

\begin{abstract}
Plasma technology has been widely applied in the ozone production, material modification, gas/water cleaning, etc. Various nanomaterials were produced by thermal plasma technology. However, the high temperature process and low uniformity products limit their application for the high value added chemicals synthesis, for example the functional materials or the temperature sensitive materials. Microplasma has attracted significant attentions from various fields owing to its unique characteristics, like the highpressure operation, non-equilibrium chemistry, continuous-flow, microscale geometry and self-organization phenomenon. Its application on the functional nanomaterial synthesis was elaborately discussed in this review paper. Firstly, the main physical parameters were reviewed, which include the electron temperature, electron energy distribution function, electron density and the gas temperature. Then four representative microplasma configurations were categorized, and the proper selection of configuration was summarized in light of different conditions. Finally the synthesis, mechanism and application of some typical nanomaterials were introduced.
\end{abstract}

Keywords Microplasma $\cdot$ Microdischarge $\cdot$ Nanomaterial synthesis $\cdot$ Functional material · Plasma technology

Qi Wang

Q.Wang1@tue.nl

1 Laboratory of Chemical Reactor Engineering/Micro Flow Chemistry and Process Technology, Department of Chemical Engineering and Chemistry, Eindhoven University of Technology, P.O. Box 513, 5600 MB Eindhoven, The Netherlands 


\section{Introduction}

Plasma is generally referred to as the fourth state of substrate, which is usually described as a mixture of fully or partially ionized gas [1]. Due to the presence of a diversity of energetic species such as electrons, ions, atoms, charged particles and excited molecules, plasma is applied to stimulate the chemistry especially the ones that can hardly be realized in mild ways, e.g. methane reforming [2-5], $\mathrm{CO}_{2}$ conversion [6-8], VOC decomposition [9-11], surface treatment of polymer surfaces [12-15], medical treatment [16-20], material synthesis [21-25], etc. Plasma technology is commercialized and industrialized in the fields of ozone production, material surface modification, air/water cleaning, medical facilities, etc., which has already shown promising energy effects and economic benefits.

Nanomaterial synthesis is widely realized through non-plasma related methods, like chemical vapor deposition (CVD) [26-28], solvothermal routes [29-31], sol-gel methods [32-34], laser ablation [35-37], etc. Fine quality products could be obtained when the starting materials and processes were properly chosen and controlled by non-plasma methods. However, it's normally difficult to control the distribution of nanoparticle size due to the extremely long reaction time. Besides, the post treatments like washing or annealing to improve products' chemical purity or crystallinity are always required, resulting in complex steps which are time and energy consuming, thus limiting their industrial applications [38].

Compared with the named non-plasma technology which uses thermal energy from high temperature, a plasma-based technology uses energy from plasma discharges to activate precursors. Therefore, it allows the use of temperature sensitive or low reactive precursors. Besides, the plasma-based technology always has unique properties such as the ability to produce nanomaterials with the freedom of choice in constituents, along with "chosen" properties such as the crystallinity and morphology [39]. Series of plasma-based technology like spark plasma sintering, thermal plasma expansion or plasma-enhanced chemical vapor deposition (PECVD) were developed over decades. And a wide range of nanomaterials were synthesized under different conditions, for example, carbides nanosized powders such as WC [40], TiC [41], TiCN [42], SiC [43-45], nitrides nanomaterials such as TiN [46-49], AlN [50-52], $\mathrm{Mg}_{3} \mathrm{~N}_{2}$ [53], GaN [54], BN [55], oxides nanomaterials such as $\mathrm{Al}_{2} \mathrm{O}_{3}$ [56], [57], $\mathrm{SnO}_{2}$ [58], $\mathrm{V}_{2} \mathrm{O}_{5}$ [59], $\mathrm{ZnO}$ [60], $\mathrm{TiO}_{2}$ [61] and metal nanoparticles such as $\mathrm{Ag}, \mathrm{Cu}, \mathrm{Fe}$ [62-64].

Plasma was also applied for producing carbon materials over the past decades, among which two typical examples were carbon nanotubes (CNT) [65-69] and carbon black (CB) [70-72]. Nowadays one intensively studied field is the production of carbon black by thermal plasma, where there were two competing and patented processes exist [73]. One was the Kvaerner process developed in Norway, in which carbon black and hydrogen gas were produced from the hydrocarbons like methane, biogas or natural gas by thermal plasma $[74,75]$. Another was the three-phase arc plasma process developed in France [71, 76-78], in which hydrocarbons were decomposed in an arc plasma reactor. Compared with other method, both methods are very energy efficient and can almost convert all the hydrocarbons.

Till now, a number of plasma processes for nanomaterial fabrication were developed. Currently there has been an increase in the number of reports about the plasma assisted nanomaterial synthesis. However, most of the existed plasma technology for nanomaterial synthesis are normally designed and operated at low pressure which necessitates expensive vacuum equipment and is not in favor of industrialization. The spatial scale of the 
reaction volume involved in these reactors is always large, leading to the difficulty to control a uniform temperature, concentration and residence time distribution environment for particle nucleation and growth, thus the produced products are commonly characterized by partial agglomeration and wide size distribution [79]. In addition, the surmised mechanism for nanomaterial synthesis includes the collisions between radical moieties in gas phase, which can be enhanced substantially at high pressures [80]. Therefore, a plasma technology for high quality nanomaterial synthesis which can be easily operated and controlled under atmospheric pressure is needed.

This could possibly be addressed by the recent developed technique of microscale plasma - microplasma, which is a special category of plasma confined within sub-millimeter length scale in at least one dimension [81]. In virtue of the increased surface-tovolume ratio and the decreased electrode spacing, microplasma boasts several key advantages compared with conventional plasma: the high-pressure operation, non-equilibrium chemistry, continuous-flow, microscale geometry and self-organization phenomenon [80]. In general, it possesses the characteristics of the conventional plasma but combined with microscale geometry, resulting in a new and novel branch of plasma science. Based on these reasons, microplasma is intensively researched in recent years for their potential applications in a wide range of fields.

Besides the above mentioned unique chemistry, microplasma offers the possibility of preserving strong non-equilibrium state in a wide range of gas mixtures [82], allowing for high reaction rates, and enabling a large number of fast and efficient high-throughput processes [79]. Since the micro reactor geometry can limit the particle nucleation and growth by controlling a short residence time with a narrow RTD, the production of narrowsize distributed nanoparticles is easy to achieve. On the other hand, the microscale also makes it easy to realize discharge under high pressure, along with the reduction of safety risks when handling toxic materials. By virtue of the above mentioned advantages, in latest years there have been more researches on functional nanomaterial synthesis by microplasma, although it retains a disadvantage of low product output as a result of the small scale dimension. In this paper, the state of the art for the fabrication of nanomaterials by microplasma is going to be discussed.

The comparison of different methods for nanomaterial synthesis was summarized in Table 1.

Table 1 Methods for nanofabrication with their advantages and drawbacks

\begin{tabular}{lll}
\hline Methods & Advantages & Drawbacks \\
\hline $\begin{array}{l}\text { Non-plasma } \\
\text { related } \\
\text { methods }\end{array}$ & $\begin{array}{c}\text { Products with high purity and good quality when raw } \\
\text { materials and processes are well selected and } \\
\text { controlled }\end{array}$ & $\begin{array}{l}\text { High energy consumption } \\
\text { Long reaction time }\end{array}$ \\
$\begin{array}{c}\text { Conventional } \\
\text { plasmas }\end{array}$ & $\begin{array}{l}\text { Simple, clean, efficient and flexible } \\
\text { Products with chosen constituents } \\
\text { process }\end{array}$ & $\begin{array}{c}\text { Requires low pressure or } \\
\text { high temperature }\end{array}$ \\
& & $\begin{array}{l}\text { Expensive reactors } \\
\text { Products with wide size } \\
\text { distribution }\end{array}$ \\
Micro-plasmas & $\begin{array}{c}\text { Atmospheric pressure operation } \\
\text { Simple, efficient, safe, economical } \\
\text { Products with high uniformity }\end{array}$ & $\begin{array}{l}\text { be solved by microplasma } \\
\text { arrays }\end{array}$ \\
\hline
\end{tabular}




\section{Microplasma Parameters and Applications}

According to the Paschen's law, the breakdown voltage of a discharge for a certain gas is a function of the pressure and the gap length between two electrodes. Microplasma is a type of plasma which is generated in a micro scale discharge gap (at submillimeter level) under atmospheric pressure. Except the advantages of short residence time and narrow RTD, another significant feature of microplasma is its non-equilibrium state, in which the gas temperature $\mathrm{T}_{\mathrm{g}}$ is much lower than the electron temperature $\mathrm{T}_{\mathrm{e}}$. There are mainly two reasons. Firstly, the electrons exchange energy via collisions with the other radicals such as ions or neutrals. When plasma is confined in a micro zone, the collision rate increases significantly, as well as the average energy exchanged. Therefore, reducing plasma size at constant pressure leads to an increase of electron temperature. Secondly, due to the high surface-to-volume ratio, the heat coupled from the power supply dissipates immediately and doesn't accumulate. The non-equilibrium state provides new pathways for nanomaterial fabrication that cannot be achieved by conventional ways and especially favors the synthesis of temperature sensitive materials as well as the use of temperature sensitive precursors.

In order to get insights into the intricate features of microplasma, systematic diagnostic studies of different types of microplasma have already been carried out. The parameters characterizing microplasma feature such as the electron temperature $T_{e}$, electron energy distribution functions (EEDFs), the electron density $n_{e}$ and the gas temperature $T_{g}$ have been measured and calculated by various established techniques.

\section{Electron Temperature and Energy Distribution Functions}

The electron temperature, $T_{e}$, determines the energy of electrons in microplasma, while the EEDFs reflect the distribution of energetic electrons. Both of them have a deep impact on

Table 2 Several experimental examples on the measurement of $T_{e}$

\begin{tabular}{|c|c|c|c|c|c|c|}
\hline $\begin{array}{l}\text { Power } \\
\text { coupling }\end{array}$ & Gases & $\begin{array}{l}\text { Discharge } \\
\text { distance } \\
(\mu \mathrm{m})\end{array}$ & $\begin{array}{l}\text { Pressure } \\
(\mathrm{kPa})\end{array}$ & $\mathrm{T}_{\mathrm{e}}$ & $\mathrm{n}_{\mathrm{e}}$ & Reference \\
\hline DC & $\mathrm{Ar}$ & 250 & 101.33 & $1 \mathrm{eV}$ & $\begin{array}{l}10^{15} \\
\mathrm{~cm}^{-3}\end{array}$ & {$[87,88]$} \\
\hline $\begin{array}{l}\text { DC couping } \\
10 \mathrm{~ns} \\
\text { pulses }\end{array}$ & $\mathrm{Ar}$ & 250 & 101.33 & $2.25 \mathrm{eV}$ & $\begin{array}{l}10^{16} \\
\mathrm{~cm}^{-3}\end{array}$ & {$[87,88]$} \\
\hline DC & $\mathrm{Xe}$ & 100 & 53.33 & \multirow{2}{*}{$\begin{array}{l}\text { Increased more than an order of } \\
\text { magnitude when coupling } 20 \text { ns } \\
\text { pulses }\end{array}$} & & [89] \\
\hline $\begin{array}{l}\text { DC couping } \\
20 \mathrm{~ns} \\
\text { pulses }\end{array}$ & $\mathrm{Xe}$ & 100 & 53.33 & & & [89] \\
\hline DC & $\begin{array}{r}\mathrm{Ne} / \\
\mathrm{H}_{2}\end{array}$ & 100 & 99.06 & $\begin{array}{l}\text { Confirm the presence of } \mathrm{Ne}_{2}^{*} \text { with } \\
\mathrm{T}_{\mathrm{e}} \text { above } 17 \mathrm{eV}\end{array}$ & & [83] \\
\hline DC & $\begin{array}{r}\mathrm{He} / \\
\mathrm{H}_{2}\end{array}$ & 250 & 80.00 & $\begin{array}{l}\text { Confirm the presence of } \mathrm{He}_{2}^{*} \text { with } \\
\mathrm{T}_{\mathrm{e}} \text { above } 20 \mathrm{eV}\end{array}$ & & [84] \\
\hline $\mathrm{DC}$ & $\mathrm{Ar}$ & 600 & $40-93.33$ & $0.9 \pm 0.3 \mathrm{eV}$ & $\begin{array}{l}10^{15} \\
\mathrm{~cm}^{-3}\end{array}$ & [85] \\
\hline
\end{tabular}


the process in nanomaterial synthesis. The high energy electrons enable efficient, nonthermal dissociation of vapor precursors and other molecular gases to form reactive radical species. The EEDFs allow the production of high concentrations of those species in a certain $\mathrm{T}_{\mathrm{e}}$ range. The higher electron temperature always leads to a rapid increase of "effective" collision among the radicals and results in an enhancement of average energy of them. As a consequence, more radicals for nanofabrication can be obtained during ionization processes.

According to the researches on microplasma characterization, there are mainly two factors affecting the non-thermal state of plasma: the non-transient effect and the micro dimension, which can be adjusted by applying the pulsed discharges or by changing the electrodes' distance. As mentioned above, the difference between the electron temperature and gas temperature determines the plasma's non-thermal state. In this section the measurement of the electron temperature are provided, along with a brief summary (Table 2) and some representative examples on the two factors and the corresponding electron temperatures [83-85], followed by a general statement of EEDFs in microplasma.

Normally the electron temperature could be measured by an optical emission spectroscopy or by the Thomson scattering based method. In the former one, the microplasma is the source of an intense excimer emission. Through the line intensity measurements by an optical emission spectroscopy the plasma electron temperature could be measured. In the latter method, the free electrons of plasma accelerate and radiate in the oscillating field under the effect of the high power laser, they have thermal velocity and cause the Dopplershift from the incident laser wavelength. By measuring the formed Doppler shifted scattered spectrum, the electron temperature can be determined [86].

Frank and his co-workers [87, 88] measured the electron temperature in an $\mathrm{Ar}$ microdischarge which was driven by a DC power supply. They found that the mean electron temperature was about $1 \mathrm{eV}$, which was less than half of the value (about $2.25 \mathrm{eV}$ ) when applying nanosecond pulses to the DC microdischarge. Another example is shown by Moselhy et al. [89], they researched the Xe excimer emission in a DC generated microdischarge by applying electrical pulses with 20 ns duration, and were able to increase more than an order of the magnitude of the Xe excimer emission over a DC discharge, which also indicated the existence of a significant fraction of high energy electrons in microplasma. The raise of electron temperature when coupling pulsed discharge to the DC plasma could be attributed to the electron heating effect, since it allows to heat electrons while simultaneously keep the gas temperature unchanged.

As to the micro dimension, a typical example is using an Argon plasma sustained between a capillary exit and a substrate (the distance can be changed) to study the relationship between the electron/gas temperatures and the micro dimension [82]. The results showed that micro discharges exhibited the non-equilibrium characteristics. And reducing the plasma size always leads to the increase of the electron temperature. Since the plasma volume is reduced, a better power coupling from the electrical fields to the electrons could be obtained, resulting in the increase of electron temperature. Electron temperature as high as $14 \mathrm{eV}$ could be achieved when the distance between the substrate and the capillary exit was reduced to $0.2 \mathrm{~mm}$.

In different microplasma conditions and configurations, the electron temperature varies significantly from each other, so does the electron energy distribution. Although there are no specific results on the relationship between EEDFs and other parameters, one common result is that the electron energy distribution in microplasma is not following Maxwellian distribution, which has already been verified by experimental studies [90] and simulations [91]. 
A typical experiment was conducted between two parallel plate electrodes separated by $200 \mu \mathrm{m}$, which reflecting the electron and ion kinetics in atmospheric pressure He DC microplasma [92]. In their experiments, various locations with different distances to the cathode were investigated, and the EEDFs were tested. The results indicated that three groups of electrons can be identified according to their energy: low energy electrons $(<1 \mathrm{eV})$, mild energy electrons $(1-20 \mathrm{eV})$ and high energy electrons $(>20 \mathrm{eV})$. Reflected by the significant high energy tail attributed to the acceleration of electrons near the cathode, the high energy electrons are abundant in this regime. In the bulk region, the high energy tail disappears because the electric field is much lower than the sheath area. The density of mild energy electrons also changes drastically with their energy, but is less than the low energy electrons. This result proves again that the electron energy distribution functions are not following the Maxwellian distribution.

\section{Electron Density}

Another important parameter to characterize microplasma is the electron density, $\mathrm{n}_{\mathrm{e}}$, which varies significantly with the electrodes distance, pressure, power, gas component and so on. Compared with conventional plasmas, microplasma can be operated at a higher pressure due to the possible breakdown of "pressure times discharge distance" scaling, indicated by the Paschen's law. As a result, the higher density energetic species such as electrons or other charged particles can be obtained in microplasma. In nanofabrication process, the high electron density can enhance the collision rates of precursors to produce high concentration of radical moieties, resulting in more efficient processes for the particle formation and growth, especially highly favorable for the nanomaterial synthesis. In this section the electron density measurement is introduced, along with some typical examples of experimental parameters and the corresponding electron densities.

The electron density varies in different conditions, and it could be measured by the Stark broadening technique or by the optical emission spectroscopy (OES) line-ratio method. Experiment diagnostics demonstrate that the Stark broadening technique has a fundamental limitation when the electron density is in the range between $10^{13}$ and $10^{16}$ $\mathrm{cm}^{-3}$. It is because the presence of resonance known as the van der Waals and the Doppler broadenings, where the sum of low electron density may dominate the line broadening. The OES line-ratio method is a good option when measuring the electron density in such a range. While in the range of $10^{16}-10^{18} \mathrm{~cm}^{-3}$, the Stark broadening technique is a better alternative [93].

Many studies have been carried out to characterize the electron density of microplasma. The results show that it differs largely in various setups, for example, the electron density of glow discharge under atmospheric pressure was found in the region between $10^{9}$ and $10^{13} \mathrm{~cm}^{-3}$, in cases such as non-uniform discharges like atmospheric pressure microplasma jet, this value could be between $10^{14}$ and $10^{15} \mathrm{~cm}^{-3}$ [81]. For the microwave excited microplasma in argon near atmospheric pressure, the value could be more than $1 \times 10^{14} \mathrm{~cm}^{-3}$. The other factors, such as pressure, power, plasma dimension and operating gas also have an impact on the electron density.

Some general features have been observed in many unbounded microdischarges at atmospheric pressure. A higher electron density will be obtained by operating at a narrower discharge gap with a constant power. A higher power input will not change the electron density but only lead to an expansion of the discharge volume [94, 95]. This is because the small spatial size of plasma always has a relative large surface-to-volume ratio, resulting in a relative high ionization degree, which is benefit for obtaining a higher electron density. 
Generally the electron density was the highest at the middle of the discharge gap and decreased along the way to each electrode. McKay et al. [96] researched various RF atmospheric pressure $\mathrm{He}$ microplasmas with the frequencies ranging from $10 \mathrm{MHz}$ up to $2.45 \mathrm{GHz}$, and found that the electron density was in the order of $10^{17} \mathrm{~m}^{-3}$ when the electrodes were separated by a distance of $500 \mu \mathrm{m}$, and it varied in different positions. However in bounded microdischarges, the electron density associates not only with gap distance but also with input power. A RF (144.0 MHz) microplasma jet with different powers was studied by $\mathrm{J}$ A Souza-Correa et al. [97], where the electron density increased from $0.35 \times 10^{15}$ to about $1.29 \times 10^{15} \mathrm{~cm}^{-3}$ by increasing the power from $5 \mathrm{~W}$ to $50 \mathrm{~W}$.

\section{Gas Temperature}

The gas temperature is another important parameter that must be considered in the process of nanomaterial synthesis. A high gas temperature can result in coagulation and spheroidization effects, leading to a significant thermal damage to the temperature sensitive precursors, products or substrates involved, sometimes even cause the evaporation of solid objects. This problem is more severe in microelectronic manufacturing industry where the high gas temperature always easily exceed the melting points of some metallic interconnects [1]. Microplasma is termed as the non-equilibrium low-temperature plasma because the electron temperature is much higher than the neutral and ion temperature. The non-equilibrium feature makes it a good choice for nanomaterial synthesis, especially for temperature sensitive materials. In this section some interesting examples are provided, along with the introduction of the gas temperature measurement.

There are normally two methods to measure the gas temperature in plasma. One is by measuring the Doppler profile of emission or absorption lines, which is due to the velocity distribution of atoms. Through the degree of Doppler broadening the translational temperature can be determined [98], [99]. The $\mathrm{N}_{2}$ s positive system can also be adopted to estimate the gas temperature, according to the study of M. Bazavan et al. [100], the electron temperature is generally much greater than the gas temperature, while the rotational temperature is equal with the gas temperature. Therefore, by modeling the $\mathrm{N}_{2}$ emission spectra of the molecular rotational bands belong to the $\mathrm{N}_{2 \mathrm{~s}}$ positive system, the rotational temperature in the microplasma can be obtained [100].

The gas temperature is in close connection with the discharge current and the gas composition. Generally it is higher for molecular gases and lower for rare gases. The pressure also has a significant impact on the temperature [101]. By observing the rotational profile of the band of the second positive $\mathrm{N}_{2}$ system in atmospheric pressure air microplasma, the gas temperature was measured to range from 1700 to $2000 \mathrm{~K}$ when regulating the discharge current from 4 to $12 \mathrm{~mA}[102,103]$. As to a microplasma generated in a hollow cathode metal tube, the value was approximately $1200 \mathrm{~K}$ for pure Ar and kept constant at different discharge currents. When nickelocene or copper acetylacetonate was introduced to the plasma, the value was estimated to be 1200 and $1500 \mathrm{~K}$ at the current of 4 and $8 \mathrm{~mA}$ respectively [104]. Also the gas temperature depends strongly on pressure [105]. It increases from about $380 \mathrm{~K}$ at $50 \mathrm{mbar}$ to around $1100 \mathrm{~K}$ at $400 \mathrm{mbar}$ in the $\mathrm{Ar}$ microplasma.

As can be seen from above, compared with conventional plasmas, microplasma has a relatively higher electron temperature as well as a larger electron density, also its uniquely featured non-equilibrium thermodynamics makes it particularly suitable for nanomaterial synthesis. Besides, more potential applications in various fields are being studied and investigated currently. 


\section{Microplasma Applications}

Owing to its unique characteristics, a series of important, sometimes novel applications are being exploited with the development of the microplasma technology, among which one particularly promising and suitable application is for nanomaterial synthesis. Table 3 shows a comparison of some features valued by nanofabrication process between microplasma and conventional plasma. A more detailed elaboration about the microplasma application will be discussed in "Microplasma Configurations for Nanomaterial Fabrication" and "Nanomaterials Fabricated by Microplasma and Their Applications" sections.

Thanks to the high reactivity and relatively low operation cost, microplasmas have been studied for the environmental application, especially for the destruction of the volatile organic compounds (VOCs) such as ethylene, benzene, toluene and octane. Becker [106] and his colleagues researched comprehensively on several types of microplasmas and their use in the remediation of VOCs and biological decontamination. They obtained the maximum VOCs destruction efficiency between 90 and $100 \%$ for all researched compounds. Takafumi Seto et al. [107] developed a miniaturized DBD microplasma device for the decomposition of VOCs in the gas phase. The results showed that for a batch system the toluene decomposition efficiency was almost $100 \%$, while for a flow system the efficiency was more than $80 \%$.

A number of researches have concentrated on the use of microplasma for biological systems. Since microplasma can inactivate microorganisms like cells, viruses, bacteria, spores, biofilms, it has been used as a tool for inactivation, sterilization and bio-decontamination [101, 106, 108]. Jerzy Mizeraczyk et al. [106] investigated an atmospheric pressure microplasma generated by $\mathrm{Ar}$ and $\mathrm{Ar} / \mathrm{O}_{2}$ microwave for biomedical applications. They performed several biocidal tests of samples treated by $\mathrm{Ar}, \mathrm{Ar} / \mathrm{O}_{2}(0.5 \%)$ and $\mathrm{Ar} / \mathrm{O}_{2}$ (1\%) microplasma, and found that there was a reduction of bacteria population for all treated samples. Becker et al. [109] used capillary plasma electrode reactors in different gas mixtures such as pure $\mathrm{He}, \mathrm{He} / \mathrm{air}, \mathrm{He} / \mathrm{N}_{2}$ and air to study the inactivation of Bacillus subtilis spores and Bacillus stearothermophilus spores. The results showed that the decimal reduction factor (D-value, which is used to describe the time for reducing a specific active microorganism concentration by one order of magnitude) could be achieved in less than 2 min.

Another interesting application is as an ultraviolet radiation source. Since the presence of a high density of energy electrons in microplasma, it enables the excimer formation for gases. Many researchers studied extensively on rare gases such as $\mathrm{He}$ [110], $\mathrm{Ne}$ [111], Ar

Table 3 Comparison between microplasma and convention plasma for features in nanofabrication processes

\begin{tabular}{|c|c|c|}
\hline Aspects & Microplasma & Convention plasma \\
\hline Operating pressure & Atmospheric pressure & Always needs low pressure \\
\hline Gas temperature & $\begin{array}{l}\text { Can be as low as room } \\
\text { temperature }\end{array}$ & Always needs temperature above $1000^{\circ} \mathrm{C}$ \\
\hline $\begin{array}{l}\text { Particle size and } \\
\text { distribution }\end{array}$ & $\begin{array}{l}\text { Fine size, narrow size } \\
\text { distribution }\end{array}$ & $\begin{array}{l}\text { Relative larger size and wider size } \\
\text { distribution }\end{array}$ \\
\hline Setup and its investment & $\begin{array}{l}\text { Quite small, easily moved, low } \\
\text { cost }\end{array}$ & Always large, fixed, high cost \\
\hline
\end{tabular}




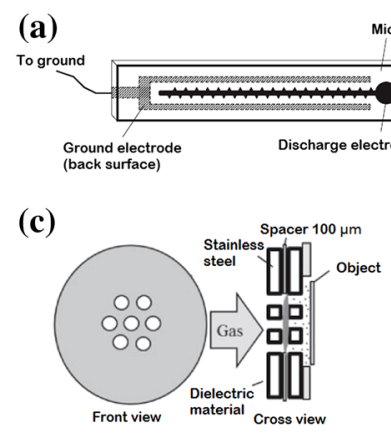

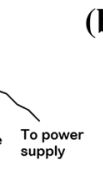

(d)

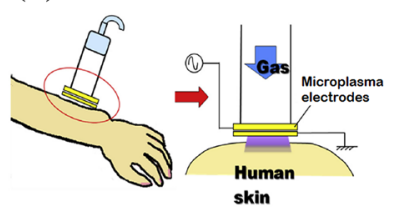

(b) Metal-organic

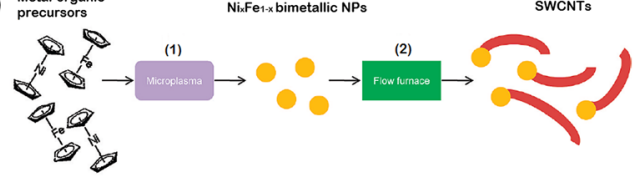

(e)

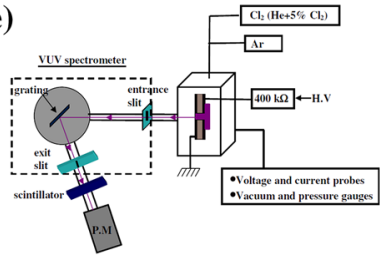

Fig. 1 Important applications of microplasma. a Destruction VOCs (reprinted with permission from [107], copyright 2005 The Japan Society of Applied Physics). b Synthesis of biometallic nanoparticles (reprinted with permission from [121], copyright 2009 American Chemical Society). c Surface treatment (reprinted with permission from [116], copyright 2012 The Japan Society of Applied Physics). d Surface sterilization treatment of human skin (reprinted with permission from [120], copyright 2014 Elsevier). e Ultra violet radiation sources (reprinted with permission from [122], copyright 2011 IOP Publishing)

[112], $\mathrm{Xe} \mathrm{[113]} \mathrm{or} \mathrm{rare} \mathrm{gas} \mathrm{halide} \mathrm{mixtures} \mathrm{like} \mathrm{XeCl}$ [114], and concluded that up to $8 \%$ internal efficiencies was approached by Xe excimer microplasma sources, while for heavier rare gases, lower efficiencies were achieved. As to the rare gas halide mixtures, efficiencies of the order of a few percent have been measured. With the advances in the design of microplasma arrays, there is a promising of using them as large area light sources both in visible and ultraviolet spectrums.

Microplasma has also been intensively studied for its application in surface treatment of glasses or polymers $[115,116]$. In industries such as the display manufacturing, eye glasses and automobile side-view mirrors, hydrophilic property is required to make electrical connections between flat-panel surfaces, or to keep the glass surface transparent under mist conditions. As mentioned above, there are abundant active species and radicals in the microplasma environment, which can activate the molecules or atoms on the surface of glasses or polymers. With such interactions the surface will be modified and a hydrophobic layer could be formed to improve their hydrophilic property [117].

Other applications like biomedical diagnostics [118], spectroscopic analysis [119] and medical treatment of human skin [120] were also reported and under development. Figure 1 illustrates several important applications of microplasma that have been reported in recent years [107, 116, 120-122].

\section{Microplasma Configurations for Nanomaterial Fabrication}

So far various microplasma configurations have been developed and used in different applications. Generally the classification could be made based on the power sources, ranging from DC power supply to other different kinds of radio frequency from $\mathrm{kHz}$ to GHz. Also it could be classified by different electrode geometries, such as dielectric barrier discharges (DBDs) [123], hollow electrode discharges [124], micro-cavity discharges [125], microplasma jets [126], microplasma arrays [127] and so on. Figure 2 shows several microplasma systems with different electrode geometries. 
(a)

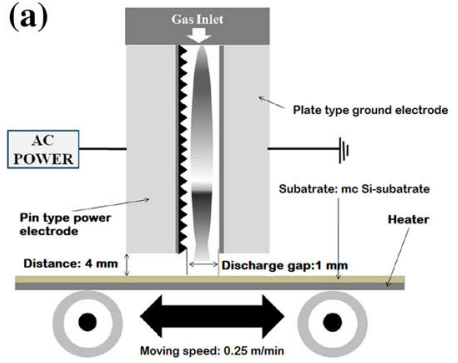

(d)

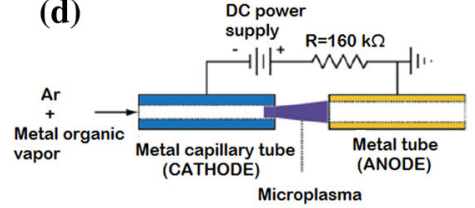

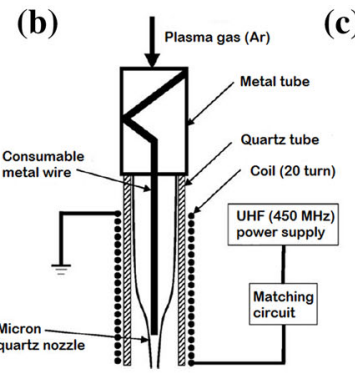

(c)

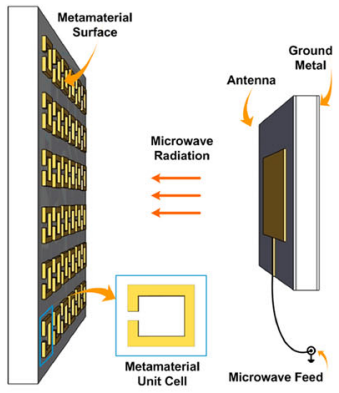

(e)

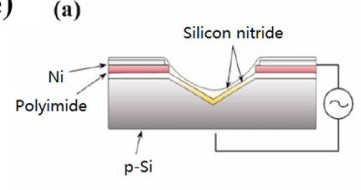

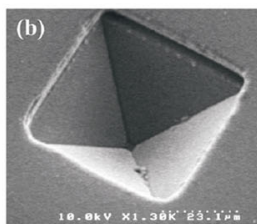

Fig. 2 Different types of microplasma systems classified by electrode geometries. a DBD microplasma (reprinted with permission from [123], copyright 2005 IOP Publishing). b Micro-cavity discharges (reprinted with permission from [125], copyright 2006 IOP Publishing). c Microplasma arrray (reprinted with permission from [127], copyright 2014 Macmillan Publishers Ltd). d Hollow electrode discharges (reprinted with permission from [124], copyright 2010 IOP Publishing). e Microplasma jet (reprinted with permission from [126], copyright 2006 Elsevier)

\section{Hollow-Electrode Microcharges}

Hollow-electrode microcharges are relatively simple structures used for nanomaterial fabrication and can be operated stably at atmospheric pressure and room temperature. Generally there are two hollow metal capillary tubes separated by 1-2 mm, both are connected to a DC power supply and act as the cathode and the anode respectively. Meanwhile, they also function as the precursor transporters, in which precursor vapors are introduced by a flow of inert gas such as Ar or He, and dissociated in the plasma area between two electrodes. The formed aerosol particles can be collected by an electrostatic precipitator or by a filter installed after the reactor. In an emblematical hollow-electrode microcharge, the typical voltage and current used to prepare nanomaterials are at the level of hundred $\mathrm{V}$ and several $\mathrm{mA}$, which are too small to ionize electrodes. Therefore, electrodes won't take part in the reactions.

In a representative structure developed by Chiang and Sankaran [128], microplasma was formed between two electrodes which were separated by $2 \mathrm{~mm}$. The cathode was a stainless steel capillary tube with an inner diameter of $180 \mu \mathrm{m}$, the anode was a stainless steel tube/mesh, and both were sealed inside a quartz tube to keep stable plasma operation. During the discharge process, the size and distribution of the generated nanoparticles could be measured by the followed aerosol size classification. In addition, they used the produced nanoparticles as catalysts for carbon nanotubes (CNTs) growth in a tube furnace, and studied catalytic properties of various compositionally-tuned $\mathrm{Ni}_{\mathrm{x}} \mathrm{Fe}_{1-\mathrm{x}}$ nanoparticles. The two-stage microplasma system is schematically illustrated in Fig. 3.

A similar microplasma reactor as Fig. 3 was used to produce multimetallic nanoparticles by the dissociation of organmetallic vapors [129]. The organmetallic compounds such as $\mathrm{Ni}(\mathrm{Cp})_{2}, \mathrm{Fe}(\mathrm{Cp})_{2}, \mathrm{Cu}(\mathrm{acac})_{2}, \mathrm{Pt}(\mathrm{acac})_{2}$ were used, and a series of mono-, bi-, and tri- 


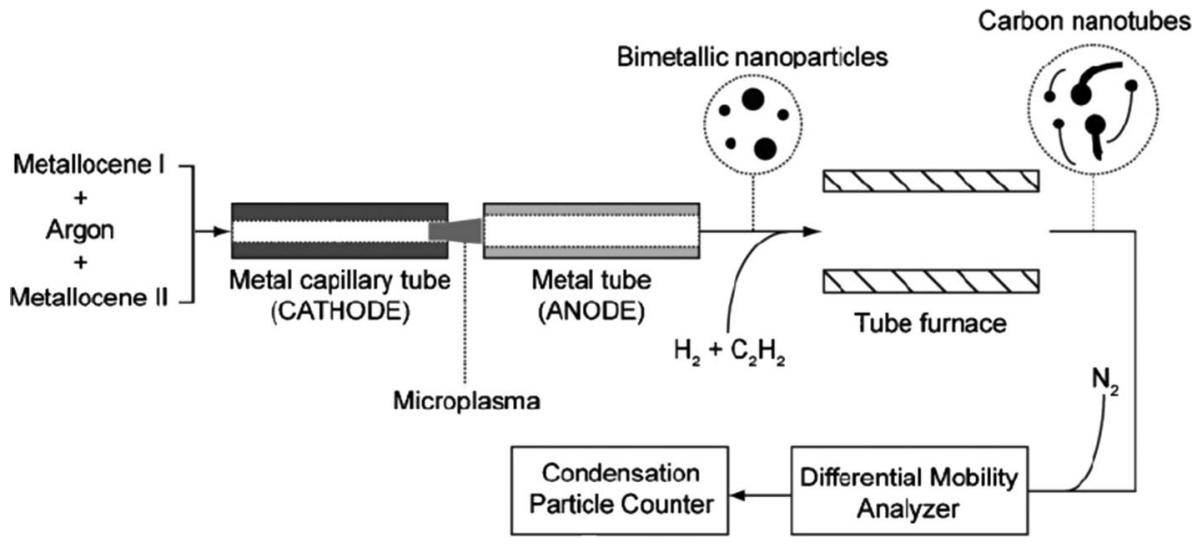

Fig. 3 The two-stage hollow-electrode microcharges. Reprinted with permission from [128], copyright 2008 Wiley-VCH

metallic nanoparticles with various compositions were synthesized by varying the flow rate of precursors. Ultra-fine (less than $5 \mathrm{~nm}$ in diameter) nanoparticles with narrow size distribution could be fabricated because of the extremely short residence time (about $1 \mathrm{~ms}$ ) in such micro-structure.

In addition to preparing metal nanoparticles and CNTs, hollow-electrode microcharges were also used to prepare Si nanowire [104] or nanodiamonds [130]. The results showed that this novel approach could produce ultrafine nanoparticles at atmospheric pressure and room temperature.

\section{Microplasma Jets}

Currently various configurations of microplasma jets were proposed and used as nanomaterial fabrication tools, with different types of power supplies (dc, rf or microwave) to ignite and sustain the plasma. Gas jets with external electrodes, like wire electrode or tube electrode, were built. Belmonte et al. [81] pointed out that the following three items should be addressed concerning microplasma jets: (1) Controlling the location of the deposition area by regulating the precursors' flow - currently the most common way is locating capillaries where the precursors flow through. (2) Managing consumable wires that were used as nanomaterial sources - most of the microplasma jets use the consumable wires as precursors of the to-be-built nanostructures; the wire is consumed as the reaction goes on. (3) Coupling the power supply (dc, rf or microwave) to the system to form plasma - the power supply has strong influence on the growth of nanomaterials, and various approaches were adopted based on the configuration of setup. Several representative examples of microplasma jets are shown in Fig. 4. Based on whether to use consumable wires as electrodes or not, there are two categories of microplasma jets.

\section{Microplasma Jets with Consumable Wires as Electrodes}

As mentioned above, the consumable wires were used as precursors in many microplasma jets. Therefore, metal wires such as W [126, 131], Fe [126], Cu [126], Mo [79, 132-134] 
(a)

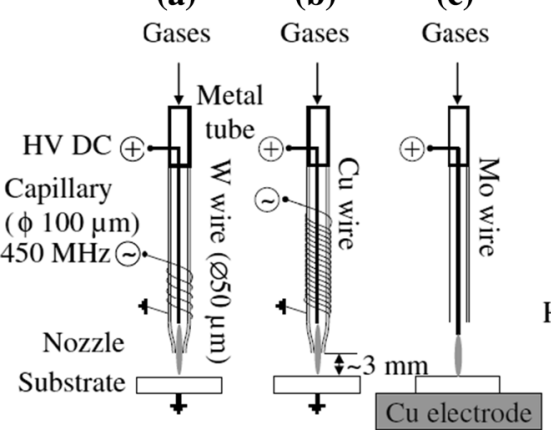

(d)

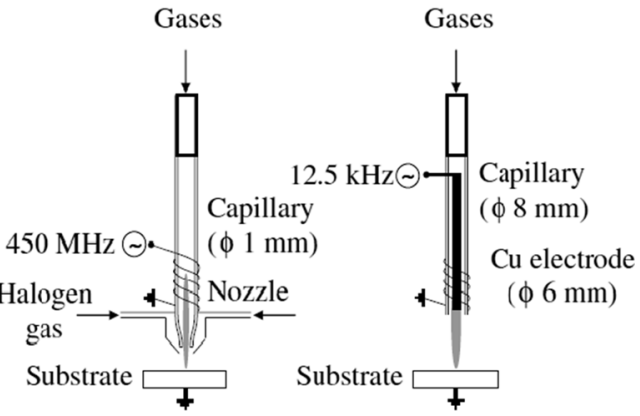

Fig. 4 Representative examples of microplasma jets. Reprinted with permission from [81], copyright 2011 IOP Publishing

and $\mathrm{Au}$ [135] were reported to be used for preparing desired nanomaterials. Table 4 summaries the main reports using consumable wires for nanomaterials preparation.

Generally the microplasma jets using consumable wires as electrodes were quite similar in their configurations. Usually a metal wire was used as the solid precursors and inserted inside a capillary tube. Various plasma gases such as $\mathrm{Ar}, \mathrm{He}, \mathrm{N}_{2}, \mathrm{H}_{2}, \mathrm{O}_{2}$ or their mixtures flew through the capillary tube to form the plasma. According to the different ways of coupling the power supply, microplasma could be formed inside or outside the tube. A part of the metal wire resided within the microplasma volume, and reactions would take place on its surface. In such a configuration, different nanomaterial structures could be obtained on the wire surface or on the substrate below the plasma jet [136]. During the deposition process, process parameters such as the gas flow rate, gas composition, substrate distance and input power can be varied to produce a wide range of nanomaterial structures. The results showed that this approach is a cost-effective and versatile way to produce metal/ metal-oxide nanomaterials compared with other methods.

A representative configuration is shown in the Fig. 4c [133]. A Mo wire $(100 \mu \mathrm{m}$ diameter) was used as the precursor as well as the electrode and connected to a high voltage power supply $(5 \mathrm{kV})$. A Si substrate was placed above the copper electrode and used for the collection of nanomaterials. Ar and $\mathrm{O}_{2}$ mixtures were introduced during the

Table 4 Microplasma jets using consumable wires as electrodes to prepare nanomaterials

\begin{tabular}{|c|c|c|c|c|}
\hline Metal wires & Plasma gas & Power supply & Structures & References \\
\hline $\begin{array}{l}\text { Mo wire, } \\
\qquad \mathrm{d}=100 \mu \mathrm{m}\end{array}$ & $\mathrm{Ar}+2 \% \mathrm{O}_{2}, 20 \mathrm{sccm}$ & $\begin{array}{l}\text { UHF (450 MHz), } \\
\text { 20/31 W }\end{array}$ & $\begin{array}{l}\mathrm{MnO}_{\mathrm{X}}-\mathrm{NPs}, \\
\mathrm{NSs}\end{array}$ & $\begin{array}{l}{[79,132-} \\
134]\end{array}$ \\
\hline Au wire, $d=100 \mu \mathrm{m}$ & $\begin{array}{c}\mathrm{Ar}+4 \% \mathrm{H}_{2} \\
200 \mathrm{sccm}\end{array}$ & $\begin{array}{l}\text { UHF (450 MHz), } \\
0.8 \mathrm{~W}\end{array}$ & $\mathrm{Au}-\mathrm{NPs}$ & {$[135]$} \\
\hline $\begin{array}{l}\text { W wire, } d=50 / \\
100 \mu \mathrm{m}\end{array}$ & $\begin{array}{c}\mathrm{Ar}+1 \% \mathrm{O}_{2} \\
5-40 \mathrm{sccm}\end{array}$ & UHF (450 MHz), $20 \mathrm{~W}$ & $\mathrm{WO}_{\mathrm{X}}$-NPs & {$[126,131]$} \\
\hline Fe wire, $\mathrm{d}=100 \mu \mathrm{m}$ & $\mathrm{Ar}, 0.5 \mathrm{sccm}$ & UHF (450 MHz), $20 \mathrm{~W}$ & $\mathrm{Fe}-\mathrm{NPs}$, NSs & {$[126]$} \\
\hline $\mathrm{Cu}$ wire, $\mathrm{d}=100 \mu \mathrm{m}$ & Ar, $30 \mathrm{sccm}$ & UHF (450 MHz), $20 \mathrm{~W}$ & $\mathrm{Cu}-\mathrm{NSF}$ & {$[126]$} \\
\hline
\end{tabular}

NPs nanoparticles, NSFs nanostructure films, NSs nanostructures 
deposition process. Ignited by a high voltage pulse, microplasma was sustained between the Mo wire tip and the Si substrate by an ultrahigh frequency (450 MHz) power supply, finally the $\mathrm{MoO}_{\mathrm{x}}$ nanomaterials could be obtained.

\section{Microplasma Jets with Tubes/External Electrodes}

There are also reports using tubes or external electrodes instead of the consumable wires to form plasma jets. In that case, extra precursors such as $\mathrm{CH}_{4}$ [137, 138], $\mathrm{SiCl}_{4}$ [139], $\mathrm{Ti}\left[\mathrm{OC}_{3} \mathrm{H}_{7}\right]_{4}[140,141], \mathrm{Pd}(\mathrm{hfac})_{2}$ [142] and $\mathrm{Cu}(\mathrm{hfac})_{2}$ [142] are provided to prepare the desired products. Table 5 summaries the main reports using tube or external electrodes to prepare nanomaterials by microplasma jets.

Compared with the microplamas using consumable wires as electrodes, this type of microplasma jet has a higher degree of flexibility in configuration. Since there are more available ways to couple the power supply to the system, a wider range of process parameters could be set, like precursors ratio, power coupling mode, residence time and so on. Furthermore, in addition to metal/metal-oxide nanomaterials, this method can also produce other nanomaterials by dissociating corresponding precursors, making it possible to prepare more products with different structures.

One typical example of the microplasma jet with tube electrodes is shown in Fig. 5 [143]. A hollow WC tube was used as the cathode electrode and Ar carrier, and connected to a RF (13.56 MHz) power supply via a matching circuit. During the experiments, a microplasma jet was formed at the tip of the WC tube and contacted directly with a

Table 5 Microplasma jets with tube/external electrodes to prepare nanomaterials

\begin{tabular}{|c|c|c|c|c|}
\hline Precursors & Plasma gas & Power supply & Structures & References \\
\hline $\mathrm{CH}_{4}, \mathrm{H}_{2}$ & $\mathrm{He}, 30 \mathrm{sccm}$ & $\begin{array}{l}\mathrm{RF}(15-35 \mathrm{kHz}) \\
100 \mathrm{~W}\end{array}$ & CNTs & [137] \\
\hline $\mathrm{CH}_{4}$ & $\begin{array}{l}\mathrm{Ar}+0.5 \% \mathrm{CH}_{4}, \\
200 \mathrm{sccm}\end{array}$ & $\begin{array}{l}\mathrm{UHF}(450 \mathrm{MHz}), \\
5-30 \mathrm{~W}\end{array}$ & $\mathrm{C}-\mathrm{NSs}$ & {$[144]$} \\
\hline Fe-coated $\mathrm{Si}, \mathrm{CH}_{4}$ & $\mathrm{Ar} / \mathrm{CH}_{4}, 50 / 50 \mathrm{sccm}$ & $\begin{array}{l}\mathrm{RF}(13.56 \mathrm{MHz}), \\
35 \mathrm{~W}\end{array}$ & $\mathrm{Si}-\mathrm{NCs}, \mathrm{CNTs}$ & {$[138]$} \\
\hline $\mathrm{SiCl}_{4}$ & $\begin{array}{l}\mathrm{Ar}+0.8 \% \mathrm{H}_{2} \\
200 \mathrm{sccm}\end{array}$ & $\begin{array}{l}\mathrm{UHF}(144 \mathrm{MHz}) \text {, } \\
35 \mathrm{~W}\end{array}$ & $\mathrm{Si}-\mathrm{NCs}$ & [139] \\
\hline $\mathrm{Ti}\left[\mathrm{OCH}\left(\mathrm{CH}_{3}\right)_{2}\right]_{4}$ & $\begin{array}{l}\mathrm{Ar}+0.1 \% \mathrm{CH}_{4} / \mathrm{N}_{2} \\
200 \mathrm{sccm}\end{array}$ & $\begin{array}{l}\mathrm{UHF}(430 \mathrm{MHz}) \\
10 \mathrm{~W}\end{array}$ & TiC/TiN-NSFs & {$[140]$} \\
\hline $\begin{array}{l}\mathrm{Ti}\left[\mathrm{OCH}\left(\mathrm{CH}_{3}\right)_{2}\right]_{4}, \\
\mathrm{O}_{2}\end{array}$ & $\begin{array}{l}\mathrm{He}, 490 \mathrm{sccm} \mathrm{O} \mathrm{O}_{2}, 10 \\
\text { sccm }\end{array}$ & $\begin{array}{l}\mathrm{RF}(13.56 \mathrm{MHz}), \\
12 \mathrm{~W}\end{array}$ & $\mathrm{TiO}_{2}-\mathrm{NSFs}$ & [141] \\
\hline $\begin{array}{l}\mathrm{Pd}(\mathrm{hfac})_{2}, \\
\mathrm{Cu}(\mathrm{hfac})_{2}, \\
\mathrm{Ni}(\mathrm{Cp})_{2}, \mathrm{O}_{2}\end{array}$ & $\begin{array}{l}\text { Ar, } 100-300 \mathrm{sccm} \\
\mathrm{O}_{2}, 10-100 \text { Torr }\end{array}$ & $\begin{array}{c}\text { DC, } 1-20 \mathrm{~mA}, \\
500-700 \mathrm{~V}\end{array}$ & $\begin{array}{l}\mathrm{CuO} / \mathrm{PdO} / \mathrm{NiO}-\mathrm{NSs} \text {, } \\
\mathrm{NSFs}\end{array}$ & [142] \\
\hline $\mathrm{CH}_{4}, \mathrm{H}_{2}$ & $\begin{array}{l}\mathrm{CH}_{4}, 10 \mathrm{sccm} ; \mathrm{H}_{2}, 350 \\
\text { sccm }\end{array}$ & RF (14 MHz) & CNTs & {$[188]$} \\
\hline $\mathrm{CH}_{4}$ & $\begin{array}{l}\mathrm{Ar}, 10-50 \mathrm{sccm} \\
\mathrm{CH}_{4}, 10-50 \mathrm{sccm}\end{array}$ & $\begin{array}{l}\mathrm{RF}(13.56 \mathrm{MHz}), \\
40 \mathrm{~W}\end{array}$ & $\begin{array}{l}\text { CNTs, CNWs, } \\
\text { Nanodiamond }\end{array}$ & [197] \\
\hline Fe-coated $\mathrm{Si}, \mathrm{CH}_{4}$ & $\begin{array}{l}\mathrm{Ar}, 10-50 \mathrm{sccm} \\
\mathrm{CH}_{4}, 10-50 \mathrm{sccm}\end{array}$ & $\begin{array}{l}\mathrm{RF}(13.56 \mathrm{MHz}), \\
35 \mathrm{~W}\end{array}$ & $\begin{array}{l}\text { CNTs, Si-NCs, Si- } \\
\text { NWs }\end{array}$ & [143] \\
\hline
\end{tabular}

$N P s$ nanoparticles, $N W$ nanowires, NSFs nanostructure films, NSs nanostructures, NCs nanocrystals 


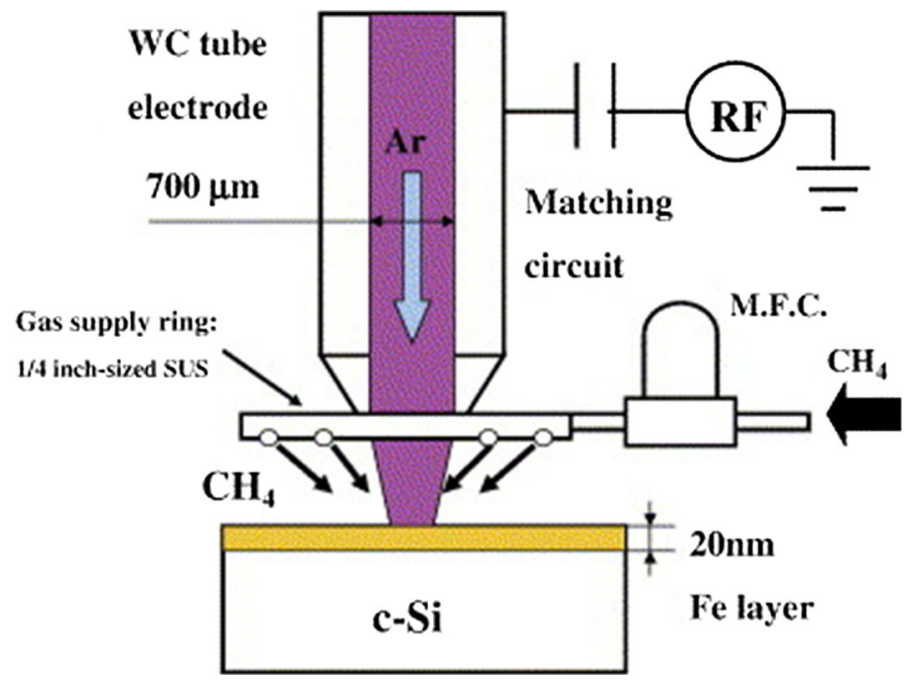

Fig. 5 Schematic diagram of microplasma jet with a WC tube as cathode. Reprinted with permission from [143], copyright 2007 Elsevier

Fe-coated $\mathrm{Si}$ substrate. $\mathrm{CH}_{4}$ was supplied to the microplasma jet through a separate gas line. In this research, variables such as the plasma exposure time, plasma power, gas flow rate and composition were studied. By plasma heating, a mixture of CNTs, Si nanowires and $\mathrm{Si}$ nanocones were produced via the combination processes of $\mathrm{FeSi}_{\mathrm{x}}$ catalytic growth, $\mathrm{Si}$ diffusion and oxidation. Another example was using a hollow microneedle as the electrode by connecting it to an AC power supply [137]. After introducing He and the precursor - gas mixtures of $\mathrm{CH}_{4}$ and $\mathrm{H}_{2}$, microplasma was ignited by applying $100 \mathrm{~W} \mathrm{RF}$ power. Compared with CVD method, a higher CNTs deposition rate could be achieved by this method even at a lower temperature. This may attribute to the plasma effect which lowered the activation barrier of CNTs growth.

A representative example of microplasma jet with external electrodes is a similar structure as the Fig. 4a [144]. A tungsten wire was inserted in a quartz tube and connected to a high DC power supply. A copper coil surrounding the quartz tube acted as the external electrode. Microplasma was ignited by a DC power supply $(15 \mathrm{kV})$ and sustained at atmospheric pressure with the external electrode. $\mathrm{CH}_{4}$ and $\mathrm{Ar}$ were used as the precursor and the carrier gas to form carbon materials without extra heating. Another similar microplasma jet with external electrodes was applied to deposit $\mathrm{TiC}, \mathrm{TiO}_{2}$ and $\mathrm{TiN}$ coatings [140]. Plasma was generated in $\mathrm{SiO}_{2}$ nozzle, which was wounded by a copper wire as the external electrode. By using titanium tetraisopropoxide as the precursor, titanium-based nanomaterials were deposited on stainless steel rods to improve their performance.

Considering the scaling-up of microplasma jet system, Cao et al. [145] studied a ten-jet microplasma array (Fig. 6) for its electrical and optical characteristics, and found that it had achieved excellent uniformity jet-to-jet both in time- and space-wise. If microplasma arrays could be properly designed and used in the process of nanomaterial synthesis, it may allow to increase nanomaterials throughput drastically and to enable the deposition of thin films in a relatively large area. 

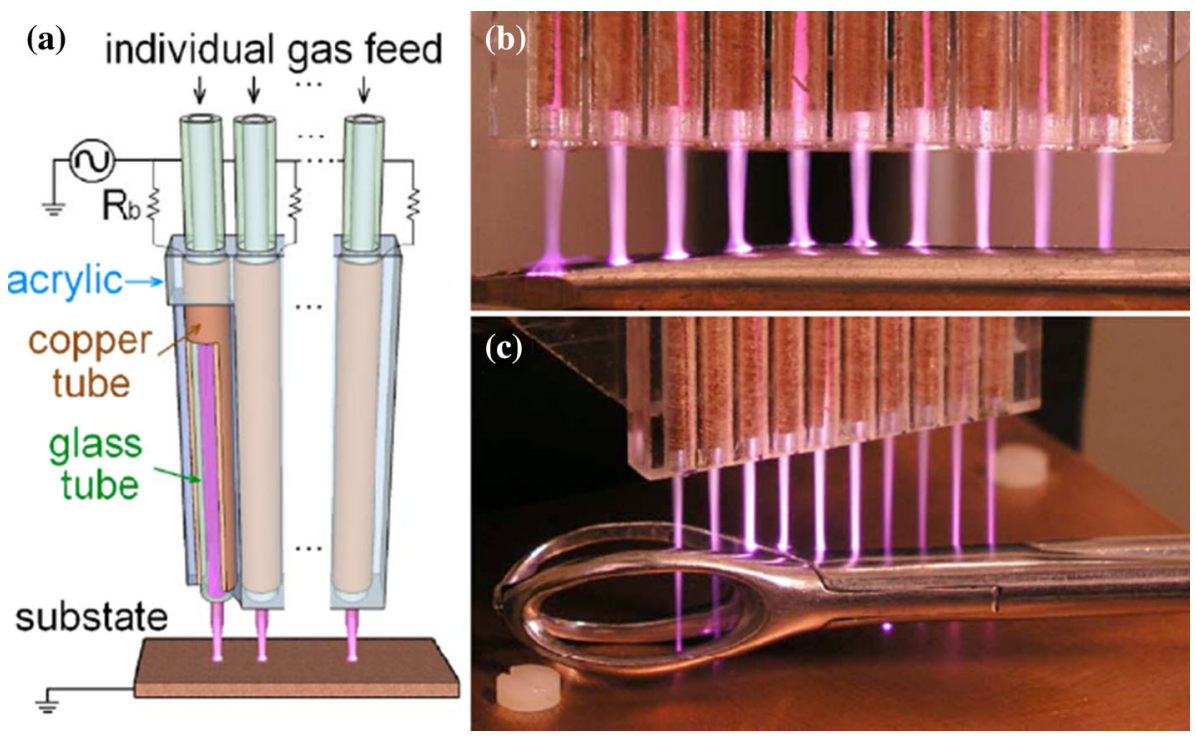

Fig. 6 The photograph of an array of microplasma jets setup. Reprinted with permission from [145], copyright 2009, AIP Publishing LLC

\section{Microtorches}

Plasma torches have been wildly used for the synthesis of nanomaterials, particularly suitable for the deposition of coatings with different performance. In most cases, gas temperatures are above $4000 \mathrm{~K}$, which are close to thermal equilibrium state [81]. The high temperature and high energy density of the plasma torch make it possible to spray refractory materials, which can't be achieved by other plasma methods. The produced nanoparticles are easily clogged under such high temperatures, leading to a broad size distribution. Plasma torches can be generated by microwave or dc arc discharge, which are shown in Fig. 7 [81]. It is worthwhile to mention that they are contamination free since they could be formed without any internal electrodes.

When the plasma torch is confined in a relative small spatial zone, it becomes "microtorch". Seriously speaking, there is no clear boundary between plasma torch and microplasma torch. However, compared with microplasma jets, the plasma formed in microtorch commonly has a larger zone and a higher gas temperature, and the produced nanomaterials always have larger sizes and a wider size distribution.

Precursors fed to microplasma torches are mainly solid or liquid. Clogging in the small discharge space should be avoided. For DC microplasma torches there are usually two approaches to introduce the precursors, as illustrated in Fig. 8 [81]. One approach is feeding precursors perpendicularly to the microplasma torch but not in contact with any electrode, as shown in Fig. 8a. In the other case, precursors could be feed axially flowing through inner electrodes, as shown in Fig. 8b. When a microplasma torch is applied for the deposition of various performance coatings, the coatings properties are mainly influenced by two factors-the particle velocity and the particle temperature [146]. To improve the quality of microplasma sprayed coatings, one effective way is to inject precursors axially along the plasma torch, allowing a longer dwelling time for precursors in the plasma zone. However, the sprayed particles may adhere to electrodes in such case, limiting the practical 
(a)

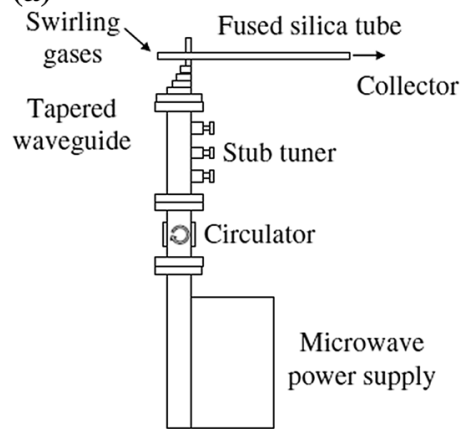

(b)

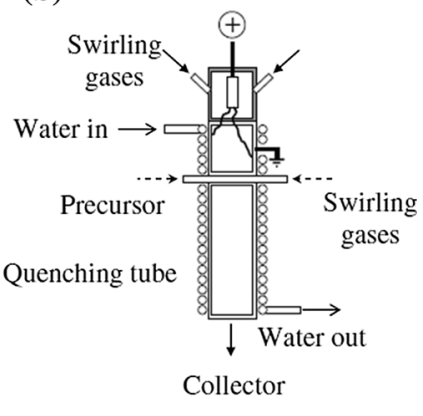

Fig. 7 Microplasma torches generated by a microwave discharge and by $\mathbf{b} \mathrm{dc}$ arc discharge. Reprinted with permission from [81], copyright 2011 IOP Publishing

Fig. 8 Two main approaches to introduce precursors to DC plasma torches. Reprinted with permission from [81], copyright 2011 IOP Publishing
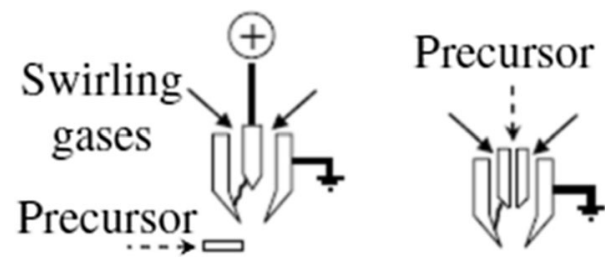

application of DC microplasma torches. Since microwave torches do not have internal electrodes, the blocking problem can be avoided.

As mentioned above, temperatures in microplasma torches are usually very high, particularly suitable for producing refractory material coatings, or handling refractory precursors. However, they are unfriendly for high quality nanoparticle synthesis, especially the heat-sensitive materials. And the particles produced by microplasma torch always have a relatively broader size distribution and are easier to agglomerate compared with the other microplasma methods. In order to prevent particle agglomeration and to improve the product quality, a quenching section becomes necessary, which helps to obtain particles with reduced size distribution. Other methods such as adding extra electrical field, confining plasma volume or reducing residence time could also be helpful to obtain high quality products.

One typical example of producing refractory nanomaterial coatings is using a hollow cathode microplasma torch to deposit $\mathrm{Al}_{2} \mathrm{O}_{3}$ coating [146], in which commercially available $\mathrm{Al}_{2} \mathrm{O}_{3}$ powder with a size distribution from 10 to $20 \mu \mathrm{m}$ was used as the precursor. Argon acted as both the operating gas and the carrier gas during the deposition process. Different plasma powers were used to deposit $\mathrm{Al}_{2} \mathrm{O}_{3}$ films, which were obtained at a $10 \mathrm{~mm}$ spray distance on a steel plate used as the substrate. The results revealed that almost the $\mathrm{Al}_{2} \mathrm{O}_{3}$ particles in the coating were well-flattened, and the particle thickness would decrease with the increase of plasma power.

\section{Liquid Phase Microplasma}

A range of approaches to generate microplasmas on/in the liquid have been developed, such as applying the DC power sources, high frequency power sources, pulsed high voltage 
power supplies and several other methods. Generally the liquid phase microplasma can be classified into two categories, the noncontact glow charge electrolysis (GDE) and the contact glow charge electrolysis (CGDE) [147]. In the former one, plasma is formed in the gas phase that above the solution surface, while in the latter case plasma is formed inside the solution. Anyhow, the plasma and the liquid interface is a ighly complex area where multiple phases (gas, liquid and vapor) exist. Moreover, charged or highly reactive species such as gaseous and solution ions, electrons and radicals make the liquid phase microplasma of promising applications in various fields. One particularly interesting application is for nanomaterial synthesis [148].

It's a new and attractive way to produce colloidal nanoparticles in an aqueous solution, where the microplasma is spatially located, and the bulk liquid still remains at the ambient condition. As we know, the liquid density is much larger than the gas density. Moving the plasma to the liquid phase allows the increasing of pressure more significantly than the gas phase plasma, resulting in an additional confinement of the plasma [80]. The highly confined and localized discharges may offer potential routes for preparing nanomaterials directly and efficiently. Furthermore, a lot of active chemical species can be generated in aqueous phase, including $\mathrm{OH} \cdot, \mathrm{O} \cdot, \mathrm{H} \cdot \mathrm{H}_{2} \mathrm{O}_{2}$ and $\mathrm{O}_{3}$, which are beneficial for nanofabrication. There are also studies showed that the water may contribute to the non-equilibrium state of microplasma. As well known, a fraction of the energy in plasma that coupling to the electrons could heat up the bulk gas. In liquid plasma, water acts as a heat sink, the heat can be quickly dissipated, thus it could prevent the gas temperature from drastic increase and preserve a non-equilibrium state [149].

For nanomaterials synthesized by the GDE method, one example was demonstrated by Huang et al. [150], in which they produced Ag nanoparticles via a microplasma-assisted electrochemistry process (Fig. 9a). A capillary SS tube acted as the cathode and was placed $2 \mathrm{~mm}$ above the surface of electrolyte. Helium was coupled as the operating gas and formed the plasma between the cathode and the electrolyte surface. A Pt foil was used as the anode and placed $3 \mathrm{~cm}$ away from the cathode, a DC power supply with a high voltage around $2 \mathrm{kV}$ was applied to ignite the plasma. They synthesized Ag nanoparticles with various sizes and dispersions by controlling different process parameters. After that, they prepared $\mathrm{Au}$ nanoparticles in $\mathrm{HAuCl}_{4}$ solution by a similar setup, which is schematic shown in Fig. 9b [151]. A SS capillary and a Pt foil acted as the cathode and the anode respectively, with $\mathrm{He}$ as the plasma gas. Au NPs were synthesized at the interfacial region where the formed plasma interacted with the solution. They found the size of Au NPs was a function of process parameters, such as solution temperature, current, and rate of stirring. In addition to the metal nanoparticles, the GDE method were also applied to produce metal-oxide nanoparticles such as $\mathrm{Fe}_{3} \mathrm{O}_{4}$ [152] and $\mathrm{Cu}_{2} \mathrm{O}$ [153].

For nanomaterials prepared by the CGDE method, one typical example was demonstrated in Fig. 10, in which Au nanoparticles of different shapes were fabricated in aqueous solutions [154]. Tungsten electrodes were separated by $0.3 \mathrm{~mm}$ and put in a vessel filled with $\mathrm{HAuCl}_{4}$ solution, while the temperature was maintained at $25^{\circ} \mathrm{C}$ by a cooling system. The plasma was ignited by a pulsed DC power supply with a frequency of $15 \mathrm{kHz}$. During the discharge process, applied voltages of 1600 and $3200 \mathrm{~V}$ were used. The solution was stirred by a magnetic stirrer, with sodium dodecyl sulfonate as a stabilizer. By this approach, Au nanoparticles around $20 \mathrm{~nm}$ in diameter with exotic shapes such as triangular, pentagonal or hexagonal were obtained.

A novel technique was used to prepare water-soluble CNTs by a setup based on the CGDE technology (Fig. 11) [155]. The microplasma was generated between two electrodes by applying high pulsed voltage. $\mathrm{O}_{2}, \mathrm{Ar}$ and $\mathrm{N}_{2}$ were used as the bubbling gases to 

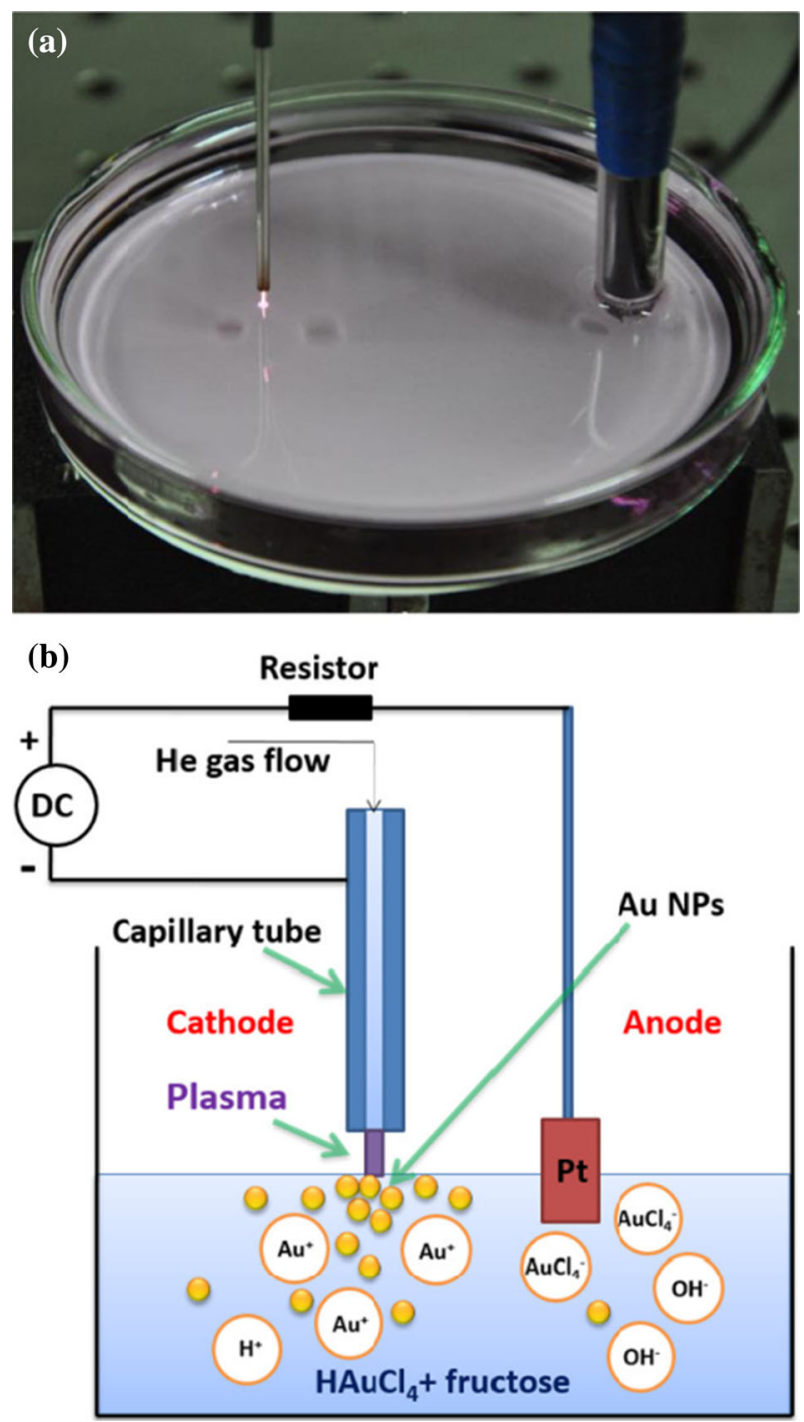

Fig. 9 The GDE experiment setup (a) and its schematic (b) for preparing Au nanoparticles. Reprinted with permission from [151], copyright 2014 Springer

enhance the discharges between electrodes. Commercial CNTs were added in deionized water, and the formed suspensions were treated by the microplasma. After one hour's treatment in a stirred tank, high water-soluble CNTs were obtained. The study showed that the high energy electrons of the microplasma could enhance the excitation and ionization of $\mathrm{H}_{2} \mathrm{O}$ molecules and lead to the generation of radicals such as $\mathrm{O}$. and $\mathrm{H}$. Then the strongly oxidative $\mathrm{O}$. reacted with $\mathrm{H}$ - to form $\mathrm{OH}$ - groups at the $\mathrm{CNT}$ surface, and the introduction of hydrophilic $\mathrm{OH}$ - groups to the CNT surface caused a higher solubility of CNTs in water. 
Fig. 10 The CGDE experiment setup for preparing $\mathrm{Au}$ nanoparticles. Reprinted with permission from [154], copyright 2008 American Vacuum Society
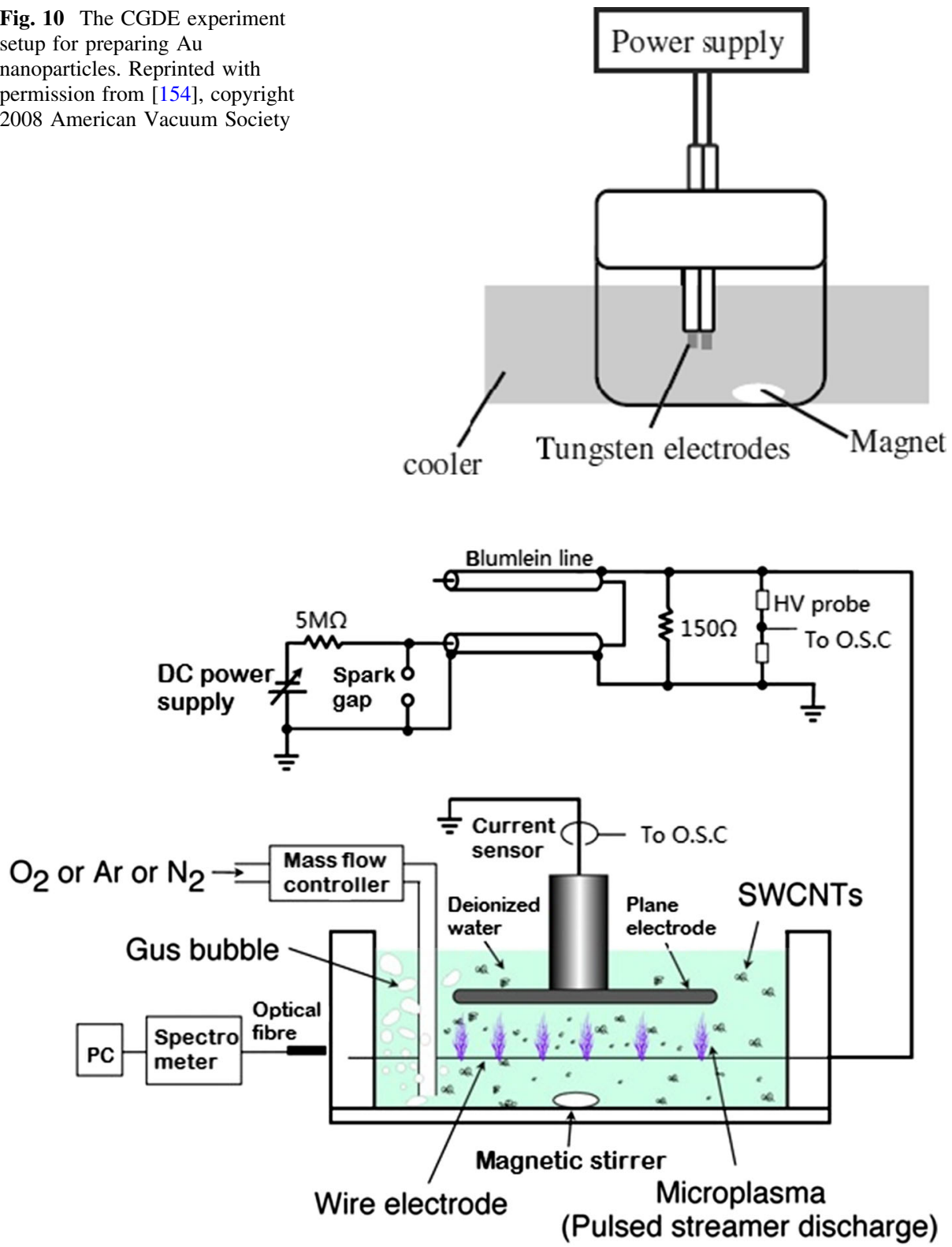

Fig. 11 Schematic experiment setup for preparing water-soluble CNTs. Reprinted with permission from [155] copyright 2007 IOP Publishing

There is a general agreement that the liquid phase microplasma would provide a potential guidance for various applications, such as the nanoparticle synthesis [150], flame electrochemistry [156], spectrochemical analysis [157], wastewater remediation [158] and so on. However, the underlying mechanism of reactions is still poorly understood, and the chemical and electrochemical processes still remain unclear. Currently just several kinds of 
nanoparticles have been produced by this method, such as $\mathrm{Au}$ [151], $\mathrm{Fe}_{3} \mathrm{O}_{4}$ [152], $\mathrm{Cu}_{2} \mathrm{O}$ [153], $\mathrm{Ag}$ [148, 159], $\mathrm{Cu}$ [160], Ti [161]. In some ways the current state of liquid phase microplasma is still considered as an "art" rather than a "precise science" [147], more investigations are needed to get those confusions solved.

\section{Selection of Appropriate Microplasma Configuration for Nanomaterial Synthesis}

The selection of microplasma configuration mainly depends on the precursors and the desired products. One benefit of microplasma is its micro-geometry. Therefore, the required quantity of precursors is quite small compared with other methods, which inevitably associates with low product output. It should be pointed out that the application of microplasma on nanomaterial synthesis may only be cost-effective for producing high value-added products or products that can't be produced by other means.

For the hollow-electrode microcharges, the electrodes also function as the "precursor carriers". Owing to their small inner diameters, the solid or liquid precursors are not allowed to be used directly in such configurations, because they can easily block the tubes. Therefore, nanomaterials can only be synthesized by the gas-phase nucleation from their precursor vapors. If a precursor is in solid or liquid state, the most common way is using another gas (often plasma gas, such as $\mathrm{Ar}, \mathrm{He}$ and $\mathrm{N}_{2}$ ) to carry its vapor to the reaction zone. If a precursor has a low vapor pressure at room temperature, the heating tape or oven can be adopted to get the desired value.

For microplasma jets and microtorches, the option for precursors has more flexibility. In principle, liquid, gas or solid can be used as precursors, although in most cases gas or solid state precursors are chosen as they are easy to handle in such configuration. There is even a report about using supercritical $\mathrm{CO}_{2}$ as the precursor to produce carbon materials by a DBD microplasma jet [162], which shows that supercritical fluid could also serve as an alternative precursor and provide a favorable environment for nanomaterial synthesis. Another attractive concept to supply precursor is evaporating or sputtering a sacrificial metal electrode, correspondingly metal nanostructures or metal oxides can be prepared, which can't be approached by other microplasma configurations. However, as mentioned, the temperatures of microtorches are usually very high, which may lead to a thermal damage to precursors that are temperature sensitive. In such cases, it's better to choose microplasma jets rather than microtorches. On the other hand, if the spherical nanoparticles are to be prepared, the microtorches are best suited, because the droplet-like nanostructures are expected to be the prominent shape in high temperatures [1].

The precursors of liquid phase microplasma are quite different from that of other kinds of plasma, and almost are electrolytes containing metal ions of the desired nanomaterials. By such device, the salts with low vapor pressures are especially suited as precursors. In addition to the metal salts, sacrificial metal electrodes are also used as precursors, which are oxidized to form metal ions in the solution and then reduced to metal nanoparticles by the impact of plasma. Compared with traditional electrochemical methods which need organic stabilizer to prevent the agglomeration or the deposition of nanoparticles on electrodes, this approach is stabilizer-free because of the free-contact of electrolytes with electrodes.

Above all, Table 6 shows a brief summary of precursors used and products obtained by the above mentioned microplasma configurations. It can be used as a guideline for process design or for choosing an appropriate type of plasma in nanomaterial synthesis. 
Table 6 A summary of precursors used and products obtained by different microplasma configurations

\begin{tabular}{|c|c|c|}
\hline $\begin{array}{l}\text { Microplasma } \\
\text { configuration }\end{array}$ & Precursors & Ever reported products \\
\hline $\begin{array}{l}\text { Hollow-electrode } \\
\text { microcharges }\end{array}$ & $\begin{array}{l}\text { Gas, liquid or solid, but liquid or solid should } \\
\text { use their vapors }\end{array}$ & $\begin{array}{l}\text { Metal NPs or alloys, } \mathrm{Si} \\
\text { nanostructures CNTs, } \\
\text { nanodiamonds, etc }\end{array}$ \\
\hline Microplasma jets & $\begin{array}{l}\text { Gas, liquid, solid or supercritical fluids, } \\
\text { especially suitable for metal wires }\end{array}$ & $\begin{array}{l}\text { Metal NPs or oxides, carbon or } \mathrm{Si} \\
\text { nanostructures, diamond } \\
\text { nanostructures }\end{array}$ \\
\hline Microtorches & $\begin{array}{l}\text { Gas, liquid or solid, but not suitable for } \\
\text { temperature sensitive precursors }\end{array}$ & Spherical metal NPs or oxides \\
\hline $\begin{array}{l}\text { Liquid phase } \\
\text { microplasma }\end{array}$ & $\begin{array}{l}\text { Metal salts or metal wires, especially suitable for } \\
\text { metal salts with low vapor pressures }\end{array}$ & $\begin{array}{l}\text { Metal NPs like } \mathrm{Au}, \mathrm{Ag}, \mathrm{Ni}, \mathrm{Ti} \text {, and } \\
\mathrm{Cu} \\
\text { Metal-oxide NPs like } \mathrm{Fe}_{3} \mathrm{O}_{4}, \mathrm{Cu}_{2} \mathrm{O}\end{array}$ \\
\hline
\end{tabular}

\section{Nanomaterials Fabricated by Microplasma and Their Applications}

Since nanomaterials exhibit unique properties that are attractive to various high performance applications, currently the nanomaterial fabrication is considered as one of the most promising research fields. Microplasma is particularly suitable for nanomaterial fabrication thanks to its unique characteristics, such as the non-equilibrium state, stable operation at atmospheric pressure and room temperature, high radical densities. It can dissociate precursors efficiently and nucleate nanoparticles from atomic level, allowing preparing nanoparticles below $10 \mathrm{~nm}$ in size through the so-called "bottom-up" way. Different configurations of microplasma setups have been developed, with a wide range of nanomaterials synthesized in recent years.

\section{Metallic Nanoparticles}

Metallic nanoparticles could be synthesized by a variety of methods, for example, using microfluidics in single-phase flows or multi-phase flows, additive-assisted synthesis, carbothermic reduction and so on. Metallic nanoparticles prepared by microplasma were already mentioned in "Microplasma Configurations for Nanomaterial Fabrication" section, the reaction mechanism and their application will be further introduced in this section.

\section{Synthesis and Mechanism}

As introduced in "Hollow-Electrode Microcharges" section, Chiang et al. [128] synthesized Fe and Ni nanoparticles from ferrocene and nickelocene respectively by a hollowelectrode microplasma system. The obtained nanoparticles were narrowly dispersed and non-agglomerated compared with other methods. Bimetallic and multimetallic nanoparticles were also synthesized in such microplasma system, such as $\mathrm{Ni}_{\mathrm{x}} \mathrm{Fe}_{1-\mathrm{x}}$ [128], $\mathrm{Ni}_{0.47-}$ $\mathrm{Cu}_{0.53}, \mathrm{Ni}_{0.18} \mathrm{Cu}_{0.82}, \mathrm{Ni}_{0.22} \mathrm{Fe}_{0.29} \mathrm{Cu}_{0.49}$, and $\mathrm{Ni}_{0.34} \mathrm{Fe}_{0.46} \mathrm{Cu}_{0.20}$ [129].

The existence of high density energetic electrons in small scale reaction zones allows the decomposition of precursors and the nucleation of nanoparticles efficiently in situ. Currently the detailed mechanism for nanoparticle nucleation and growth in microplasma is still unclear. The process may have something to do with precursors' concentration, dissociation enthalpy or other processing parameters. However, a general hypothesis of the 


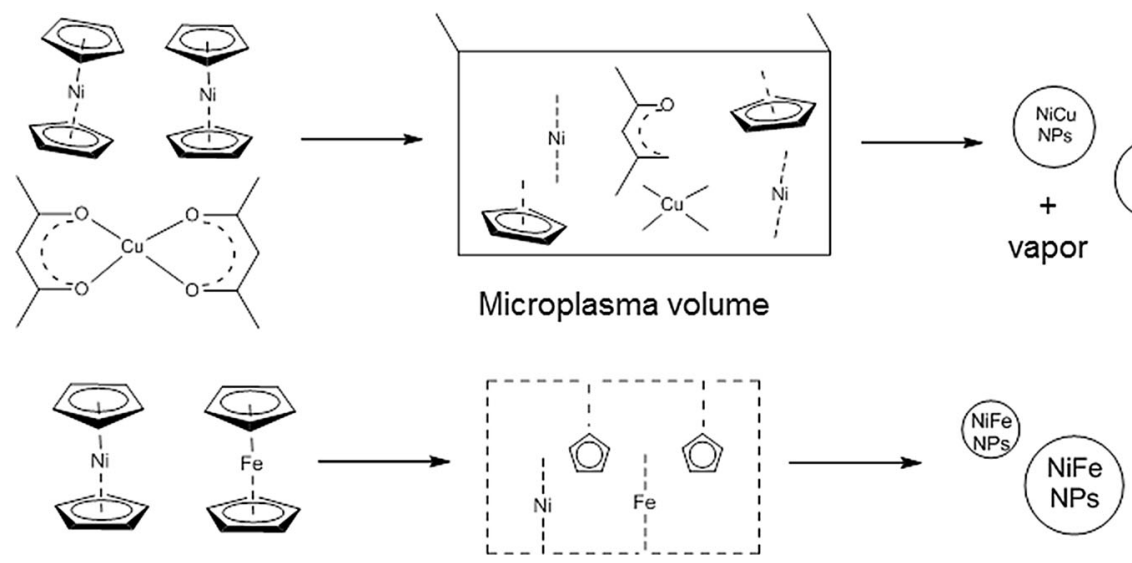

Fig. 12 The assumed mechanism of pure metal NPs and multimetallic NPs synthesis by microplasma. Reprinted with permission from [128] copyright 2011 Wiley-VCH

mechanism can be shown in Fig. 12 [129]. Organometallic compounds like $\mathrm{Ni}(\mathrm{Cp})_{2}$, $\mathrm{Fe}(\mathrm{Cp})_{2}$ and $\mathrm{Cu}(\mathrm{acac})_{2}$ vapors are dissociated in microplasma to form radical moieties such as $\mathrm{Ni} \cdot \mathrm{Fe} \cdot \mathrm{Cu} \cdot$ and $\mathrm{C}_{5} \mathrm{H}_{5} \cdot$ as the first step. Afterwards, these radicals collide with each other randomly to nucleate pure metal NPs or multimetallic NPs.

Metal nanoparticles such as Ag [148], $\mathrm{Au}$ [151], $\mathrm{Cu}$ [160] and $\mathrm{Ti}$ [161] that prepared by microplasma electrochemical method were introduced in the "Liquid Phase Microplasma" section. A potential mechanism for the nucleation of metal nanoparticles $\mathrm{M}$ from deduction of metal cations $\mathrm{M}^{+}$via GDE approach is shown in Fig. 13 [147]. Similar to the conventional electrochemical processes, there are three distinct reasons for ion transportation to the plasma-liquid interface: (1) electric field induced metal ions $\left(\mathrm{M}^{+}\right)$migration, (2) convection, (3) diffusion. In electrolytes the convective force is weak and only attributes to the free convection. There is no appreciable concentration gradient in the electrolytes except the plasma-liquid interface. As a result, the diffusion dominates only in this area. Once $\mathrm{M}^{+}$reaches the interface, they undergo electron transfer process to produce metallic $\mathrm{M}^{0}$ atoms. However, because of the inability to characterize the plasma-liquid interface by electrochemical probes, the mechanism of electron transfer process and nanoparticle nucleation still remains unclear. Once $\mathrm{M}^{0}$ atoms are obtained at the interface, they may serve as sites for nanoparticle nucleation and growth. Afterwards, the formed nanoparticles may aggregate and become large clusters or networks, then transported to electrolyte bulk by diffusion or convection process.

\section{Applications}

Metallic nanoparticles attracted immense interest in a wide range of fields such as the catalysts [128, 159], biological applications [163], medical applications [164], bio-sensing applications [165] and so on. In this section two typical examples are introduced, one is for CNTs growth and another for cancer treatment, corresponding to nanoparticles production by the gas phase microplasma and by the liquid phase microplasma respectively.

Metallic nanoparticles produced by microplasma can be used as catalysts for many processes, for example, $\mathrm{Ni}$ and Fe nanoparticles show excellent catalytic activity for CNTs growth [166]. Chiang et al. [128] used Ni and Fe nanoparticles to catalyze the CNTs growth. The results showed that the reduction of Ni nanoparticle, with the size distribution 
Fig. 13 The potential mechanism for preparing metal nanoparticles by GDE approach [147]. Reprinted with permission from [147], copyright 2013 American Vacuum Society
PLASMA

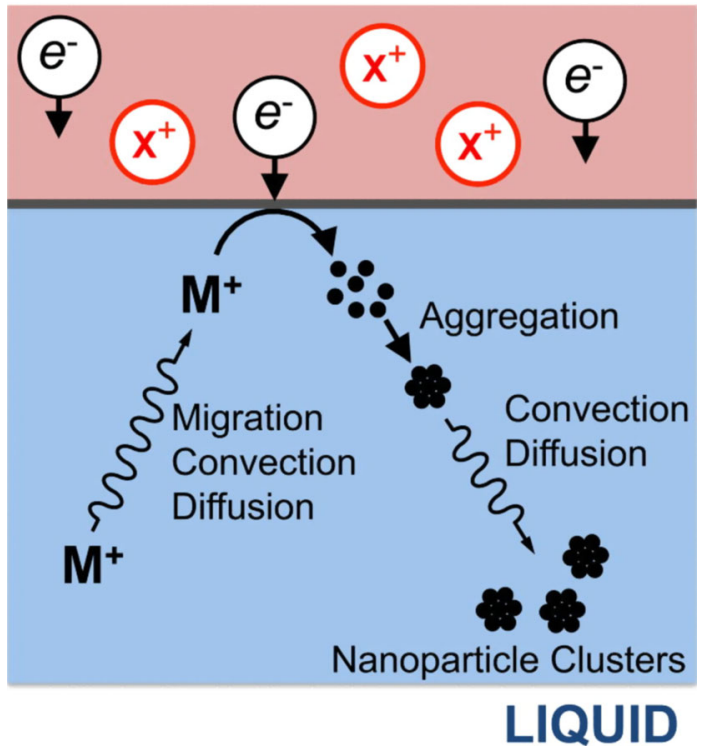

from $3.1 \mathrm{~nm}$ to $2.2 \mathrm{~nm}$, caused an improvement for the rate of CNTs growth by 13 times. Moreover, Ni nanoparticles with different dimensions could control precisely the CNTs' inner and outer diameter as well as wall numbers [167]. Afterwards, they studied the catalytic activity of the bimetallic nanoparticles, and found that $\mathrm{Ni}_{\mathrm{x}} \mathrm{Fe}_{1-\mathrm{x}}$ could significantly increase the catalytic activity and lower the activation energies for CNTs growth compared with monometallic nanoparticles [128]. For example, with $\mathrm{Ni}_{0.67} \mathrm{Fe}_{0.33}$ nanoparticles, the CNTs could grow at $300{ }^{\circ} \mathrm{C}$ with activation energy as low as $37 \mathrm{~kJ} / \mathrm{mol}$, while CNTs only grew at $400{ }^{\circ} \mathrm{C}$ with $\mathrm{Ni}$ nanoparticles and the activation energy was estimated to be $73 \mathrm{~kJ} / \mathrm{mol}$.

Metallic nanoparticles, particularly the noble metal nanoparticles, showed promising prospects in cancer treatment due to their unique characteristics such as the high surface to volume ratio, facile surface chemistry, excellent optical properties as well as the ability to convert radio frequencies or light into heat [164]. They can extravasate into tumor stroma and accumulate at tumor sites, and be tracked directly by optical microscopy because of their special optical and imaging properties. Furthermore, the noble metal nanoparticles hold great promise to kill cancer cells selectively through hyperthermia effect. Microplasma electrochemical method may become the most attractive and reliable way to prepare metal nanoparticles for biological application, since it is environment friendly without any stabilizers, the products are smaller with narrower size distribution compared with the products achieved by other methods.

\section{Si Nanomaterials}

\section{Synthesis and Mechanism}

Silicon nanoparticles were synthesized in microplasma driven by the RF power supply $[138,168]$ or DC power supply $[104,169]$ at atmospheric pressure, through different 
microplasma configurations. Silicon tetrachloride $\left(\mathrm{SiCl}_{4}\right)$ and silane $\left(\mathrm{SiH}_{4}\right)$ are the most commonly used precursors.

The Si NPs synthesized by RF microplasma jet were spherical and without any agglomeration [168], shown in Fig. 14. They were highly crystalline with the size smaller than $5 \mathrm{~nm}$. Besides, it was proved that Si NPs could be nucleated and grown at temperatures well below their crystallization threshold, which was attributed to the effective heating in the non-thermal microplasma. Another example is to synthesize the Si NPs by using $\mathrm{SiH}_{4}$ as the precursor and Ar as carrier gas, a hollow-electrode microdischarge was used to produce high quality Si nanoparticles [170, 171]. The results showed that blue luminescent Si nanoparticles with diameters in the range of 1-3 $\mathrm{nm}$ and with narrow size distribution could be obtained by this method. In addition, when $\mathrm{H}_{2}$ was introduced in the plasma, a lower possibility of $\mathrm{Si}$ condensation and a lower particle growth rate were achieved, owing to the enhanced surface passivation of Si by hydrogen [172].

Although the detailed mechanisms are different in various processes, usually the general mechanism follows a similar rule. Taking $\mathrm{SiH}_{4}$ as an example [80, 170-172], silane dissociation takes place by electron impact dissociation and allows the formation of different kinds of reactive radical species such as $\mathrm{SiH}$ - and $\mathrm{H} \cdot$, which were confirmed by their

(a)

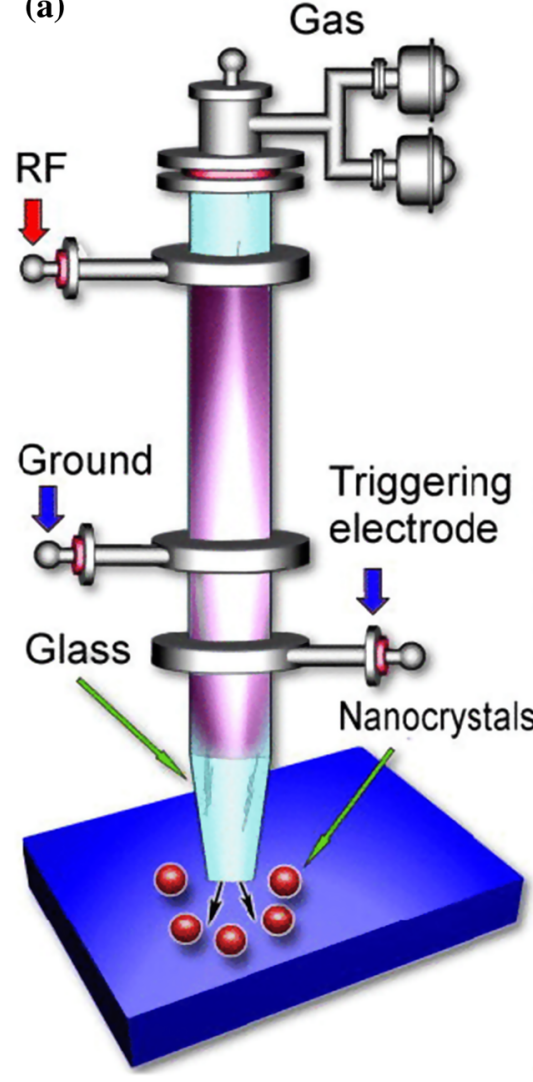

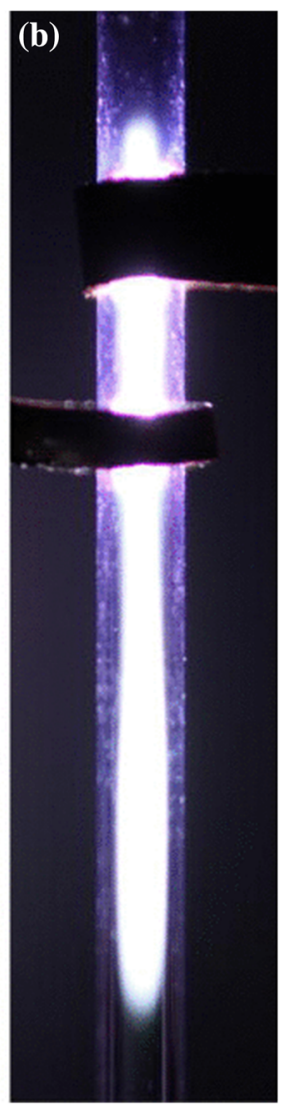

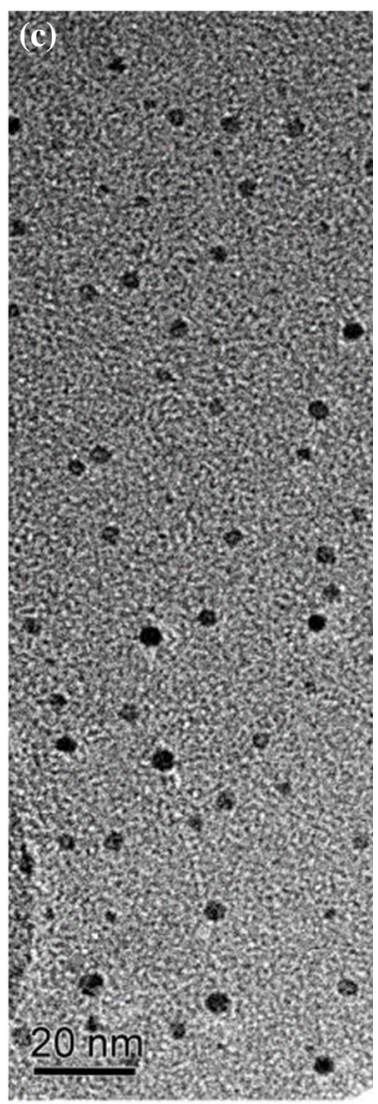

Fig. 14 Plasma setup (a, b) and the produced Si NPs (c). Reprinted with permission from [168] copyright 2014 AIP Publishing LLC 
emission lines in the OES spectra. The addition of $\mathrm{H}_{2}$ not only promotes the particle heating but also induces a transition of $\mathrm{Si}$ from amorphous state to crystalline state. Afterwards, due to their high reactivity, the formed radicals such as $\mathrm{SiH}_{3} \cdot \mathrm{SiH}_{2} \cdot \mathrm{H} \cdot$ collide and react with each other immediately to nucleate clusters via the recombination process. More and more radicals collide with those clusters, and they will grow or agglomerate by additional radical or vapor deposition on their surface or by the collisions with other clusters to form Si nanoparticles. Due to the fact of the short residence time and being charged, the particles agglomeration was suppressed, products with very good size control were obtained in the gas phase, which can be collected in the followed sections.

\section{Applications}

$\mathrm{Si}$ is one of the most abundant elements on earth, and is well known for its significant application in the semiconductor industry. However, the indirect band gap of Si elements causes the poor optical properties, limiting their application in many fields. Recently the nanostructured Si materials have spurred intense interests and are the most popular functional materials in commercial electronic industry due to the following reasons: (1) good stability and non-toxicity; (2)quantum confinement effects; (3) well-established fabrication technique; and (4) high carrier mobility [173]. It is an inspiring direction to use $\mathrm{Si}$ based nanomaterials to explore a diverse of application fields.

Among the silicon nanostructures, Si nanowires are the low-dimensional nanostructures which have unique structural, optical, electrical and thermoelectric properties [173, 174]. They have a direct band gap because of the quantum confinement, therefore, they are optically active materials suitable for photonics applications [175]. Besides, the excellent light-trapping properties of $\mathrm{Si}$ nanowires make them the low-cost and high-efficient alternatives of the traditional silicon solar cells, because they allow the orthogonalization of light absorption [176]. Besides, when they were used as lithium ion batteries' anodes, they exhibit superior electrochemical performance along with good recyclability and stability [177]. Furthermore, with the high selectivity and sensitivity, the label-free detection capability and real-time response, $\mathrm{Si}$ nanowires have shown promising prosperous in cellular recording and biomedical diagnosis applications [178].

\section{Metal-Oxide Nanomaterials}

\section{Synthesis and Mechanism}

Various microplasma configurations and processes have been developed to produce metaloxide nanomaterials. Currently the most common configuration is the microplasma jet (Fig. 4), because it is convenient to use sacrificial metal electrodes as precursors, or use tube/external electrodes with flexible precursors, allowing many approaches to couple power supply to ignite and sustain the plasma.

$\mathrm{MoO}_{\mathrm{x}}$ nanoparticles were prepared by an atmospheric pressure microplasma jet (similar to Fig. 4 (c)) using a consumable Mo wire as the electrode. Two possible mechanisms were proposed based on the gas flow rates (Fig. 15) [132]. When the gas flow rate was less than $20 \mathrm{ml} / \mathrm{min}$, the reaction and condensation effect of active species is dominant. The atomic oxygen can oxidize Mo wire surface easily, once it was oxidized the molybdenum oxides volatilize into gas phase. Then under the impact of ions and electrons, volatilized oxides were decomposed into Mo- and $\mathrm{O}$ - in the microplasma, and these radicals react and condense with each other to form Mo oxides. However, at a higher gas flow rate, the gas 


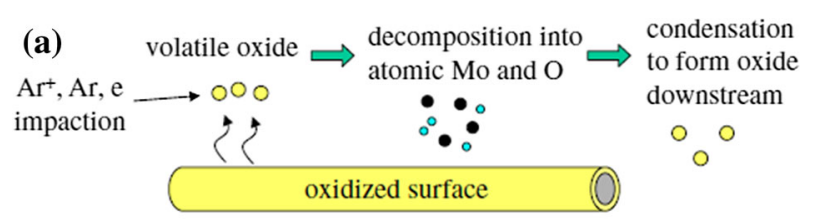

(b)

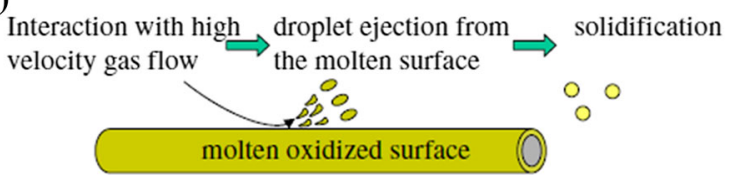

Fig. 15 Mechanisms of Mo oxides synthesis in a low gas flow rates and $\mathbf{b}$ high gas flow rates. Reprinted with permission from [132], copyright 2006 IOP Publishing

temperature was reduced, and the molybdenum wire surface was in a molten state, leading to the ejection of molten droplets to form Mo oxides NPs downstream. Therefore, the difference of mechanism is that in low gas flow rates atomic oxygen is used to oxidize both Mo and Mo wire surfaces, while in high gas flow rates it is consumed only to oxidize Mo wire.

In addition to consumable wires, organometallic precursors such as nickelocene, $\mathrm{Pd}(\mathrm{hfac}) 2$ or $\mathrm{Cu}(\mathrm{hfac}) 2$ hydrate were also used as precursors. The metal oxide nanowires such as $\mathrm{CuO}, \mathrm{PdO}$ and $\mathrm{NiO}$ were produced at different conditions [142]. There was also a report which was using a pulsed microplasma cluster source to synthesize metal oxide films by ablating metallic targets. Nanostructured $\mathrm{Mo}, \mathrm{W}$, and $\mathrm{Nb}$ oxide films with several hundreds of nanometers thickness were formed by this approach [179].

Different mechanisms were proposed for metal-oxide nanoparticles produced by microplasma jets. However, generally in every process microplasma plays two important roles [142]: (1) it dissociates precursors and provides active metal species directly, from which nanomaterials nucleate and grow; (2) it interacts with background gas to provide active oxygen species, which are an essential part of metal oxides nanomaterial synthesis. For different processes, specific mechanisms vary largely because reactions in microplasma are so complicated, since they are closely related to the type of precursors, gas flow rates, temperatures as well as other plasma parameters.

As mentioned in "Liquid Phase Microplasma" section, metal-oxide nanomaterials like $\mathrm{Cu}_{2} \mathrm{O}$ and $\mathrm{Fe}_{3} \mathrm{O}_{4}$ also can be produced by the GDE method. Compared with microplasma jet, the setup of liquid phase microplasma is much simpler, because all the nanoparticles can be collected in solution instead of substrates. Furthermore, it doesn't need to provide $\mathrm{O}_{2}$ as the precursor, for $\mathrm{O}$. can be achieved from $\mathrm{H}_{2} \mathrm{O}$. However, only DC power supply has been reported to sustain the liquid phase plasma, while for microplasma jet, various alternatives such as RF or microwave power supply systems have been reported.

\section{Applications}

Metal oxide nanostructures have the potential to play an important role in many technologies, such as the sensing devices [180], biomedical applications [181], energy conservation [182], catalysis [134], waste water treatment [183] and so on. On account of their unique mechanical and chemical properties, metal oxide nanomaterials are favored as the 
functional coating materials in various fields. This section just focuses on a promising field - the deposition of functional metal oxides coatings by microplasma. Some representative examples of functional nanomaterials will be introduced, followed by the potential way to deposit the large scale coatings using microplasma arrays.

Metal oxide nanomaterials with different performances are considered to be perfect coating materials in many applications. For example, $\mathrm{TiO}_{2}$ coated surface is hydrophilic and remain transparent under mist or rainwater because the contact angle between water and surface is small. There is hardly any water drop deposited on the coated surface. Such coatings could be used for eyeglasses or automobile side-view mirrors [184]. $\mathrm{Al}_{2} \mathrm{O}_{3}$ nanomaterial is an ideal coating material which is very attractive for the metal cutting industry because of its favorable chemical stability, excellent thermal property, great wear and deformation resistance, together with its super toughness [185]. $\mathrm{Cu}_{2} \mathrm{O}$ nanomaterials recently have received significant attentions as alternatives for Si nanomaterials in transparent conduction films, which are attributed to their excellent optical absorption properties [186]. Mo oxides coatings have also been widely used in a wide range of engineering fields due to their high melting point, excellent corrosion resistance as well as beneficial mechanical property, making it possible to control the friction and wear performance of materials over a wide range of temperatures [187].

High quality functional coatings could be obtained by microplasma technology. Compared with other methods, microplasma can produce ultra-fine nanomaterials with high uniformity. The coating process can be conducted in gas phase by the direct plasma jet/torch spraying or in liquid phase by the plasma electrochemical method. However, because of its relatively low output, one key unanswered question of microplasma technology is whether it can provide required throughout for industrial coating applications. With the growing demanding for high quality functional coatings in various fields, there is an increasing need for the deposition of large area coatings. A novel idea holding great promise for large scale deposition was proposed by adopting microplasma arrays (a typical example was shown in Fig. 6 [145] ), which can increase material output easily via arranging series of microplasmas together and operating them simultaneously. Moreover, microplasma arrays also have the potential to deposit more than one layer coatings with different performance when using a two-dimensional design, which is depicted in Fig. 16 [80]. Operated with different precursors and conditions in each array, multilayer functional

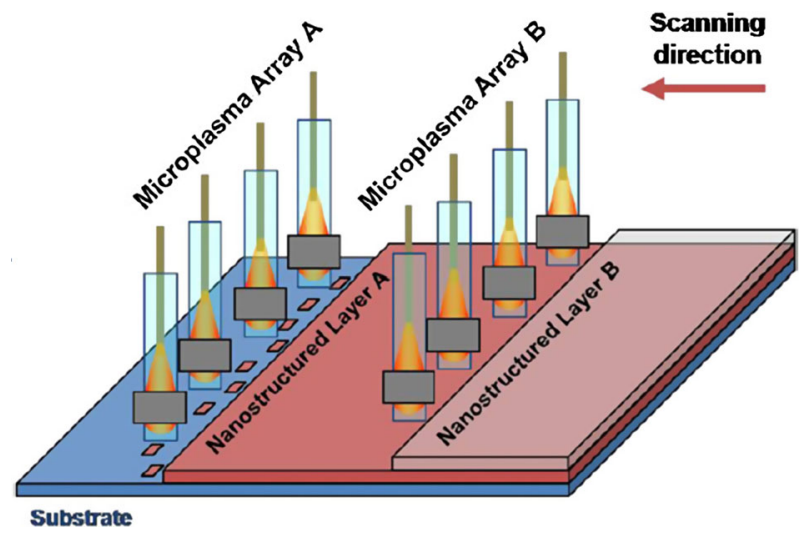

Fig. 16 Two-dimensional microplasma arrays for the deposition of multilayer coatings [80]. Reprinted with permission from [80], copyright 2010 IOP Publishing 
coatings can be obtained by scanning microplasma arrays in one direction. Therefore, if microplasma arrays were well designed, with appropriate precursors and processes, functional metal oxides coatings could be prepared in large scales by this approach.

\section{Carbon Nanomaterials}

\section{Synthesis and Mechanism}

A series of carbon nanomaterials were prepared by microplasma technology in past years, including the CNTs [128, 137, 166, 188], nanodiamonds [130, 189], nanorods [188], carbon nanoparticles [190] and so on. In this section, several typical examples were introduced.

One smart microplasma system for producing nanodiamonds at atmospheric pressure and room temperature is using the hollow-electrode microcharge configuration (Fig. 3) [130]. Ethanol vapor was chosen as the carbon source and continuously introduced to the microplasma by Ar and $\mathrm{H}_{2}$ mixture. A glass filter was installed at the exit of aerosol flow to collect nanoparticles. The results confirmed that high-purity nanodiamonds could be prepared at relatively neutral conditions by this route. Although the detailed mechanism has not been discussed yet, it was confirmed that the existence of $\mathrm{C} 2$ and $\mathrm{CH}$. species during the dissociation process would contribute to the nucleation of solid carbon clusters and nanodiamonds respectively. The introduction of $\mathrm{H}_{2}$ was affecting the diamond growth and the non-diamond carbon etching, resulting in the stabilization of diamond phase carbon and the selective removal of non-diamond phase carbon. Another example about the deposition of nanodiamond crystals was achieved by a microplasma array [189], in which four jets were operated in parallel in the capillary tubes. The deposition process was conducted at a sub-atmospheric pressure (200 Torr) chamber, with $\mathrm{H}_{2}$ and $\mathrm{CH}_{4}$ as precursors. Molybdenum foils were adopted as substrates and kept at $800{ }^{\circ} \mathrm{C}$ during the process. The results showed that the high quality diamond nanocrystals could be prepared at various $\mathrm{CH}_{4}$ concentrations (Fig. 17).

A pin-electrode microplasma configuration was used to prepare carbon nanomaterials in a SEM chamber, where a Pd needle was used as the anode and a Si wafer coated by Pt films was used as the cathode [190]. $\mathrm{CH}_{4}$ was adopted as carbon source and a pulsed high voltage power supply operated at $10 \mathrm{~Hz}$ frequency was used to sustain the plasma. Various carbon nanomaterials such as the CNTs, carbon nanoparticles or carbon nanosticks were obtained at different deposition times in this process.

The mechanisms are quite different in the processes of carbon nanomaterials synthesis, which are closely associated with deposition parameters such as the input power, gas composition, substrate temperature, catalyst, gas flow rate, etc. Generally they undergo a similar rule, the chemical bonds of carbon sources are broken by the impact of energetic electrons in microplasma. The precursors are dissociated into various radicals. These high reactive radicals collide with each other to nucleate small clusters and form nanomaterials after a series of complex processes.

One interesting phenomenon observed during carbon nanomaterial synthesis by microplasma is the self-organization. Nanomaterials prepared in plasma are always charged and interact with each other under Coulombic forces and van der Waals forces, allowing the formation of well ordered, large scale nanostructures [80]. An example system was using a stainless steel pipe as the electrode and a $\mathrm{Ni}$ wire as the substrate, in which vertically aligned CNTs were deposited on the Ni wire surface when a negative bias voltage was applied on it [188]. The studies showed that a large quantity of species such as 

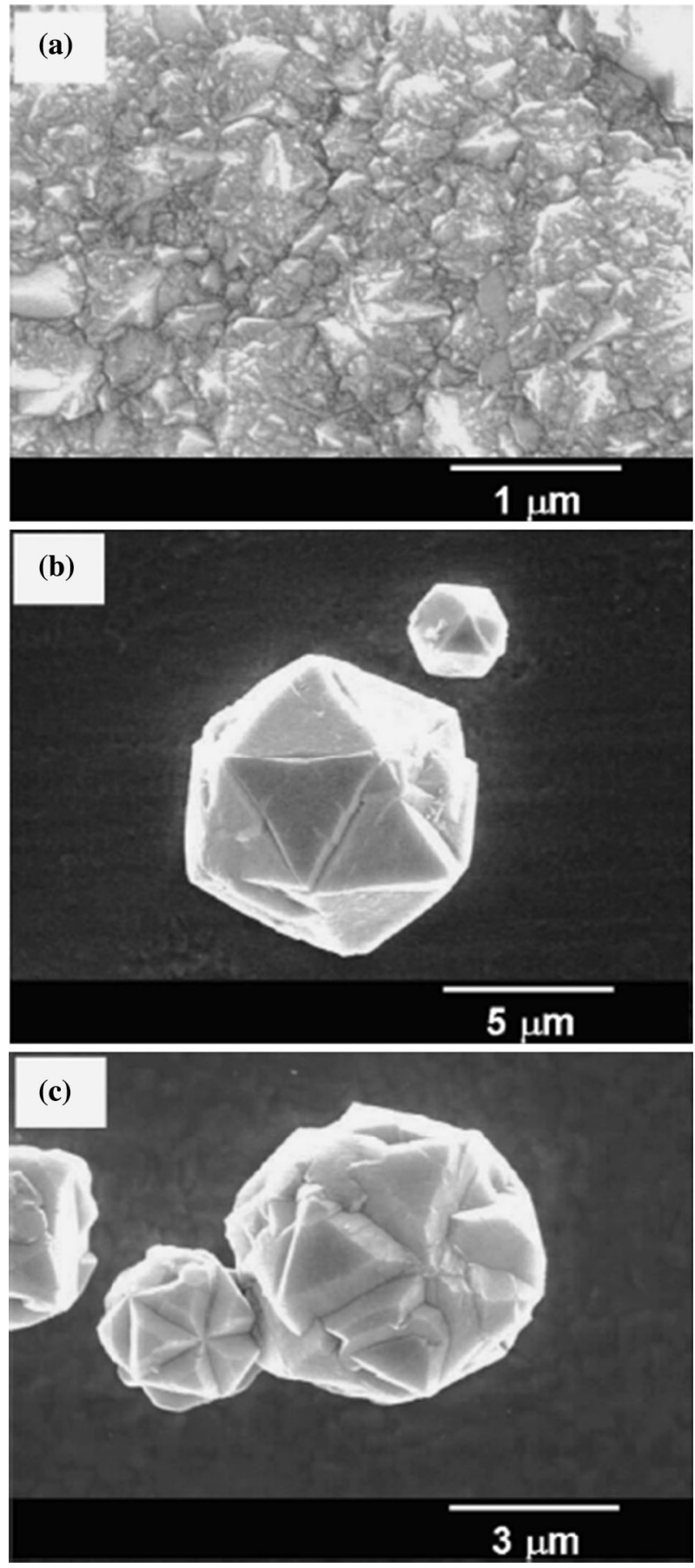

Fig. 17 Diamond film and nanocrystals produced by microplasma jets at various $\mathrm{CH}_{4}$ concentrations. a $0.5 \% \mathrm{CH}_{4}$, b $0.25 \% \mathrm{CH}_{4}$, c $0.1 \% \mathrm{CH}_{4}$. Reprinted with permission from [189], copyright 2002, AIP Publishing LLC 
$\mathrm{CH}_{3} \cdot \mathrm{CH}_{2}$ and $\mathrm{CH} \cdot$ could be obtained in the plasma. With the negative bias voltage, a perpendicular static electric field was formed on the Ni substrate, resulting in the formation of vertically aligned CNTs bundles. Another example is the formation of self-organized carbon nano-connections between the catalyst particles when exposed to a microplasma jet [191]. In the experiment, $\mathrm{CH}_{4}$ and $\mathrm{Ar}$ were introduced to form the plasma which was sustained by a UHF (450 MHz) power supply. A Si substrate coated by Ag or Fe was treated by this plasma. After the depositing process for a certain time, self-organized carbon connections were produced. The results suggested that the electric field determined the growth direction of carbon nano-connections. In this case the catalyst particles were dispersed over the substrate surface and created a two dimensional electric field. Between these two adjacent catalytic nanoparticles the electric field gradient was maximum along the straight line, which significantly affected the carbon surface diffusion and growth process. Therefore, compared with vertically aligned CNTs formed due to the electric field perpendicular to substrate, carbon nano-connections grew along the surface in virtue of the electric field along the substrate surface.

\section{Applications}

The carbon nanomaterials have attracted enormous interest for many potential applications due to their extraordinary properties. For example, nanodiamond has superior hardness, high thermal conductivity and chemical stability, so it is used as an excellent composites for filler materials [192]. With the addition of nanodiamonds to the polymers, substantial improvements in mechanical strength, thermal conductivity, adhesion and wear resistance can be obtained. Besides, they are non-toxic, biocompatible and have tunable surface chemistry, particularly suitable for biomaterials in the bone tissue engineering [193]. CNTs are also widely used for their superior mechanical properties. For example, they were adopted as reinforcement materials for polymer composites [167], implant materials [194] and scaffolds for cell encapsulation [195]. Furthermore, their high thermal conductivity makes them attractive as the cooling system materials on computer chips [196]. Increasingly potential applications will be explored and achieved in future with the developing technology of producing high-quality carbon nanomaterials at low cost.

\section{Conclusions and Outlook}

This review paper has studied the recent achievements on microplasma as an innovative tool for functional nanomaterial synthesis. The unique physical and chemical properties caused by the increased surface-to-volume ratio and the decreased electrode spacing are the main reasons that make microplasma particularly suitable for nanomaterials synthesis. Various microplasma systems were designed to fabricate nanomaterials. And the nanometer-sized, high purity and narrow size distributed products were synthesized by this unique approach.

Despite the promising perspective of microplasma technology, some challenges remain. Investigations on the mechanisms are highly required to better understand the process for nanomaterial generation. And the universality of microplasma technology for different nanomaterial synthesis should be further studied. The further development to an industrialization level of microplasma technology would require the intensive collaboration among material chemists, physicists, electrical engineers and chemical engineers. 
Open Access This article is distributed under the terms of the Creative Commons Attribution 4.0 International License (http://creativecommons.org/licenses/by/4.0/), which permits unrestricted use, distribution, and reproduction in any medium, provided you give appropriate credit to the original author(s) and the source, provide a link to the Creative Commons license, and indicate if changes were made.

\section{References}

1. Ostrikov K, Xu SY (2007) Plasma-aided nanofabrication. Wiley-VCH, Germany

2. Wang Q, Shi H, Yan B, Jin Y, Cheng Y (2011) Steam enhanced carbon dioxide reforming of methane in DBD plasma reactor. Int J Hydrog Energy 36(14):8301-8306

3. Wang Q, Cheng Y, Jin Y (2009) Dry reforming of methane in an atmospheric pressure plasma fluidized bed with $\mathrm{Ni} / \gamma-\mathrm{Al}_{2} \mathrm{O}_{3}$ catalyst. Catal Today 148:275-282

4. Wang Q, Yan BH, Jin Y, Cheng Y (2009) Dry reforming of methane in a dielectric barrier discharge reactor with $\mathrm{Ni} / \mathrm{Al}_{2} \mathrm{O}_{3}$ catalyst: interaction of catalyst and plasma. Energy Fuels 23(18):4196-4201

5. Yan BH, Wang Q, Jin Y, Cheng Y (2010) Dry reforming of methane with carbon dioxide using pulsed DC arc plasma at atmospheric pressure. Plasma Chem Plasma Process 30:257-266

6. Ihara T, Ouro T, Ochiai T, Kiboku M, Iriyama Y (1996) Formation of methanol by microwave plasma reduction of $\mathrm{CO}_{2}$ with $\mathrm{H}_{2} \mathrm{O}$. Bull Chem Soc Jpn 69(1):241-244

7. Ihara T, Kiboku M, Iriyama Y (1994) Plasma reduction of $\mathrm{CO}_{2}$ with $\mathrm{H}_{2} \mathrm{O}$ for the formation of organic compounds. Bull Chem Soc Jpn 67:312-314

8. Liu CJ, Xia Q, Zhang YP, Li Y, Zou JJ, Xu GH, Eliasson B, Xue B (2000) Converting of carbon dioxide into more valuable chemicals using catalytic plasmas. ACS Div Fuel Chem Prep 45:694-697

9. Demidiouk V, Moon S, Chae J, Lee D (2003) Application of a plasma-catalytic system for decomposition of volatile organic compounds. J Korean Phys Soc 42:966-970

10. Kim HH, Ogata A, Futamura S (2007) Complete oxidation of volatile organic compounds (VOCs) using plasma-driven catalytic and oxygen plasma. Plasma Environ Sci Technol 1:46-51

11. Jiang L, Zhu R, Mao Y, Chen J, Zhang L (2015) Conversion characteristics and production evaluation of styrene/o-xylene mixtures removed by DBD pretreatment. Int $J$ Environ Res Publ Health 12:1334-1350

12. Svirachev DM, Tabaliov NA (2005) Plasma treatment of polymer surfaces in different gases. Bulg J Phys 32:22-33

13. Slepička P, Kasálková NS, Stránská E, Bačáková L, Švorčík V (2013) Surface characterization of plasma treated polymers for applications as biocompatible carriers. Express Polym Lett 7(6):535-545

14. Borcia C, Borcia G, Dumitrascu N (2011) Surface treatment of polymers by plasma and UV radiation. Rom Rep Phys 56(11):224-232

15. Siow KS, Britcher L, Kumar S, Griesser HJ (2006) Plasma methods for the generation of chemically reactive surfaces for biomolecule immobilization and cell colonization-a review. Plasma Process Polym 3:392-418

16. Ishaq M, Evans M, Ostrikov K (2014) Effect of atmospheric gas plasmas on cancer cell signaling. Int J Cancer 134:1517-1528

17. Alshraiedeh NH, Alkawareek MY, Gorman SP, Graham WG, Gilmore BF (2013) Atmospheric pressure, nonthermal plasma inactivation of MS2 bacteriophage: effect of oxygen concentration on virucidal activity. J Appl Microbiol 115:1420-1426

18. Yang B, Chen J, Yu Q, Li H, Lin M, Mustapha A, Hong L, Wang Y (2011) Oral bacterial deactivation using a low-temperature atmospheric argon plasma brush. J Dent 39(1):48-56

19. Kostov KG, Rocha V, Koga-Ito CY, Matos BM, Algatti MA, Honda RY, Kayama ME, Mota RP (2010) Bacterial sterilization by a dielectric barrier discharge (DBD) in air. Surf Coat Technol 204:2954-2959

20. Colagar AH, Sohbatzadeh F, Mirzanejhad S, Omran AV (2010) Sterilization of streptococcus pyogenes by afterglow dielectric barrier discharge using $\mathrm{O}_{2}$ and $\mathrm{CO}_{2}$ working gases. Biochem Eng $\mathrm{J}$ 51(3):189-193

21. Lu W, Cao T, Wang Q, Cheng Y (2011) Plasma-assisted synthesis of chlorinated polyvinyl chloride (CPVC) using a gas-solid contacting process. Plasma Process Polym 8:94-99

22. Hessel V, Anastasopoulou A, Wang Q, Kolb G, Lang J (2013) Energy, catalyst and reactor considerations for (near)-industrial plasma processing and learning for nitrogen-fixation reactions. Catal Today 211:9-28

23. Anastasopoulou A, Wang Q, Hessel V, Lang J (2014) Energy considerations for plasma-assisted N-fixation reactions. Processes 2:694-710 
24. Cao TF, Zhang HB, Yan BH, Cheng Y (2013) High rate deposition of nanocrystalline silicon by thermal plasma enhanced CVD. Rsc Adv 3:20157-20162

25. Cao T, Zhang H, Yan B, Lu W, Cheng Y (2014) Optical emission spectroscopy diagnostic and thermodynamic analysis of thermal plasma enhanced nanocrystalline silicon CVD process. RSC Adv 4:15131-15137

26. Bhaviripudi S, Mile E, Steiner SA, Zare AT, Dresselhaus MS, Belcher AM, Kong J (2007) CVD synthesis of single-walled carbon nanotubes from gold nanoparticle catalysts. J Am Chem Soc 129(6):1516-1517

27. Tao X, Zhang X, Cheng J, Liu F, Luo J, Luo Z (2006) Morphology-controllable CVD synthesis of carbon nanomaterials on an alkali-element-doped $\mathrm{Cu}$ catalyst. Chem Vap Depos 12:353-356

28. Moravec $\mathrm{P}$ (2011) $\mathrm{NiO}_{\mathrm{x}}$ nanoparticle synthesis by chemical vapor deposition from nickel acetylacetonate. Mater Sci Appl 2:258-264

29. Tang KB, Qian YT, Zeng JH, Yang XG (2003) Solvothermal route to semiconductor nanowires. Adv Mater 15(5):448-450

30. Yang J, Zeng JH, Yu SH, Yang L, Zhou GE, Qian YT (2000) Formation process of CdS nanorods via solvothermal route. Chem Mater 12(15):3259-3263

31. Chauhan H, Singh MK, Hashmi SA, Deka S (2015) Synthesis of surfactant-free SnS nanorods by a solvothermal route with better electrochemical properties towards supercapacitor applications. RSC Adv. 5:17228-17235

32. Rahman IA, Padavettan V (2012) Synthesis of silica nanoparticles by Sol-Gel: size-dependent properties, surface modification, and applications in silica-polymer nanocompositesa review. J Nanomater 2012:1-15

33. Reda SM (2010) Synthesis of $\mathrm{ZnO}$ and $\mathrm{Fe}_{2} \mathrm{O}_{3}$ nanoparticles by sol-gel method and their application in dye-sensitized solar cells. Mater Sci Semicond Process 13:417-425

34. Aparna Y, Venkateswara Rao K, Srinivasa Subbarao P (2012) Preparation and characterization of CuO Nanoparticles by novel sol-gel technique. J Nano-Electron Phys 4(3):4-7

35. Ullmann M, Friedlander S, Schmidt-Ott A (2002) Nanoparticle formation by laser ablation. J Nanopart Res 4:499-509

36. Amans D, Malaterre C, Diouf M, Mancini C, Chaput F, Ledoux G, Breton G, Guillin Y, Dujardin C, Masenelli-Varlot K, Perriat P (2011) Synthesis of oxide nanoparticles by pulsed laser ablation in liquids containing a complexing molecule: impact on size distributions and prepared phases. J Phys Chem C 115:5131-5139

37. Hahn A (2008) Influences on nanoparticle production during pulsed laser ablation. J Laser Micro/ Nanoeng 3(2):73-77

38. Shimada M, Wang WN, Okuyama K (2010) Synthesis of gallium nitride nanoparticles by microwave plasma-enhanced CVD. Chem Vap Depos 16:151-156

39. Ostrikov K (2005) Reactive plasmas as a versatile nanofabrication tool. Rev Mod Phys 77:489-511

40. Grasso S, Poetschke J, Richter V, Maizza G, Sakka Y, Reece MJ (2013) Low-temperature spark plasma sintering of pure nano WC powder. J Am Ceram Soc 96:1702-1705

41. Tong L, Reddy RG (2005) Synthesis of titanium carbide nano-powders by thermal plasma. Scr Mater 52:1253-1258

42. Yang YF, Wang HY, Zhao RY, Liang YH, Jiang QC (2008) Effect of Ni content on the reaction behaviors of self-propagating high-temperature synthesis in the $\mathrm{Ni}-\mathrm{Ti}-\mathrm{B}_{4} \mathrm{C}$ system. Int $\mathrm{J}$ Refract Met Hard Mater 26:77-83

43. Rizk S, Assouar MB, Belmahi M, Le Brizoual L, Bougdira J (2007) Synthesis of SiC nanofibers by microwave plasma assisted chemical vapour deposition in $\mathrm{CH}_{4} / \mathrm{H}_{2}$ gas mixture. Phys Status Solidi (a) 204(9):3085-3090

44. Leconte Y, Leparoux M, Portier X, Herlin-Boime N (2008) Controlled synthesis of $\beta$-SiC nanopowders with variable stoichiometry using inductively coupled plasma. Plasma Chem Plasma Process 28:233-248

45. Ruiz-Camacho J, Castell R, Castro A, Manrique M (2008) Synthesis of silicon carbide in a nitrogen plasma torch: rotational temperature determination and material analysis. J Phys D Appl Phys 41:175208

46. Kakati M, Bora B, Sarma S, Saikia BJ, Shripathi T, Deshpande U, Dubey A, Ghosh G, Das AK (2008) Synthesis of titanium oxide and titanium nitride nano-particles with narrow size distribution by supersonic thermal plasma expansion. Vacuum 82:833-841

47. Tavares J, Coulombe S, Meunier J-L (2009) Synthesis of cubic-structured monocrystalline titanium nitride nanoparticles by means of a dual plasma process. J Phys D Appl Phys 42:102001

48. Khobta I, Petukhov O, Vasylkiv O, Sakka Y, Ragulya A (2011) Synthesis and consolidation of TiN/ $\mathrm{TiB}_{2}$ ceramic composites via reactive spark plasma sintering. J Alloys Compd 509(5):1601-1606 
49. Bora B, Aomoa N, Kakati M, Bhuyan H (2013) Studies on a supersonic thermal plasma expansion process for synthesis of titanium nitride nanoparticles. Powder Technol 246:413-418

50. Kim K (2005) Plasma synthesis and characterization of nanocrystalline aluminum nitride particles by aluminum plasma jet discharge. J Cryst Growth 283:540-546

51. Kulkarni NV, Karmakar S, Banerjee I, Sahasrabudhe SN, Das AK, Bhoraskar SV (2009) Growth of nano-particles of $\mathrm{Al}_{2} \mathrm{O}_{3}$, AlN and iron oxide with different crystalline phases in a thermal plasma reactor. Mater Res Bull 44:581-588

52. Rutkowski PJ, Kata D (2013) Thermal properties of AlN polycrystals obtained by pulse plasma sintering method. J Adv Ceram 2(2):180-184

53. Kim DW, Kim TH, Park HW, Park DW (2011) Synthesis of nanocrystalline magnesium nitride $\left(\mathrm{Mg}_{3} \mathrm{~N}_{2}\right)$ powder using thermal plasma. Appl Surf Sci 257(12):5375-5379

54. Hou WC, Chen LY, Hong FCN (2008) Fabrication of gallium nitride nanowires by nitrogen plasma. Diam Relat Mater 17:1780-1784

55. Lee CM, Choi SI, Choi SS, Hong SH (2006) Synthesis of boron nitride nanotubes by arc-jet plasma. Curr Appl Phys 6:166-170

56. Oh SM, Park DW (2000) Preparation of ultra-fine alumina powders by D. C. plasma jet. Korean J Chem Eng 17(3):299-303

57. Kumar S, Kang K, Bae G, Selvarajan V, Lee C (2008) Synthesis and characterization of alumina nanopowders by oxidation of molten aluminium in a thermal plasma reactor: comparison with theoretical estimation. Mater Chem Phys 11:436-441

58. Im JH, Lee JH, Park DW (2008) Synthesis of nano-sized tin oxide powder by argon plasma jet at atmospheric pressure. Surf Coat Technol 202:5471-5475

59. Kim JH, Hong YC, Uhm HS (2007) Synthesis of oxide nanoparticles via microwave plasma decomposition of initial materials. Surf Coat Technol 201:5114-5120

60. Hattori Y, Mukasa S, Toyota H, Inoue T, Nomura S (2011) Synthesis of zinc and zinc oxide nanoparticles from zinc electrode using plasma in liquid. Mater Lett 65(2):188-190

61. Banerjee I, Karmakar S, Kulkarni NV, Nawale AB, Mathe VL, Das AK, Bhoraskar SV (2010) Effect of ambient pressure on the crystalline phase of nano $\mathrm{TiO}_{2}$ particles synthesized by a de thermal plasma reactor. J Nanopart Res 12:581-590

62. Chakravarty U, Naik PA, Mukherjee C, Kumbhare SR, Gupta PD (2010) Formation of metal nanoparticles of various sizes in plasma plumes produced by Ti:sapphire laser pulses. J Appl Phys 108:053107

63. Noguez C (2007) Surface plasmons on metal nanoparticles: the influence of shape and physical environment. J Phys Chem C 111:3806-3819

64. Tavares J, Swanson EJ, Coulombe S (2008) Plasma synthesis of coated metal nanoparticles with surface properties tailored for dispersion. Plasma Process Polym 5:759-769

65. Tailleur A, Achour A, Djouadi MA, Le Brizoual L, Gautron E, Tristant P (2012) PECVD low temperature synthesis of carbon nanotubes coated with aluminum nitride. Surf Coatings Technol 211:18-23

66. Hahn J, Han JH, Yoo JE, Jung HY, Suh JS (2004) New continuous gas-phase synthesis of high purity carbon nanotubes by a thermal plasma jet. Carbon 42:877-883

67. Matsuura T, Taniguchi K, Watanabe T (2007) A new type of arc plasma reactor with 12-phase alternating current discharge for synthesis of carbon nanotubes. Thin Solid Films 515:4240-4246

68. Bystrzejewski M, Huczko A, Lange H, Płotczyk WW, Stankiewicz R, Pichler T, Gemming T, Rümmeli MH (2008) A continuous synthesis of carbon nanotubes by dc thermal plasma jet. Appl Phys A 91:223-228

69. Okada T, Kaneko T, Hatakeyama R (2007) Conversion of toluene into carbon nanotubes using arc discharge plasmas in solution. Thin Solid Films 515:4262-4265

70. Lu FK, Roseberry CM, Meyers JM, Wilson DR, Lee YM, Czysz PA (2004) Pyrolysis of methane in a supersonic, arc-heated flow. 42nd AIAA Aerospace Sciences Meeting and Exhibit. Reno, Nevada. Paper No. AIAA 2004-1132

71. Fabry F, Flamant G, Fulcheri L (2001) Carbon black processing by thermal plasma. Analysis of the particle formation mechanism. Chem Eng Sci 56(6):2123-2132

72. Baldissarelli VZ, Cassini FA, De Souza IG, Debacher NA (2014) Plasma-assisted production of carbon black and carbon nanotubes from methane by thermal plasma reform. J Braz Chem Soc 25(1):126-132

73. Moreno-Couranjou M, Monthioux M, Gonzalez-Aguilar J, Fulcheri L (2009) A non-thermal plasma process for the gas phase synthesis of carbon nanoparticles. Carbon 47(10):2310-2321

74. Bakken JA, Jensen R, Monsen B, Raaness O, Waernes AN (1998) Thermal plasma process development in Norway. Pure Appl Chem 70(6):1223-1228 
75. Naess SN, Elgsaeter A, Helgesen G, Knudsen KD (2009) Carbon nanocones: wall structure and morphology. Sci Technol Adv Mater 10(6):065002

76. Fulcheri L, Schwob Y, Fabry F, Flamant G, Chibante LFP, Laplaze D (2000) Fullerene production in a 3-phase AC plasma process. Carbon 38(6):797-803

77. Weidong X, Fulcheri L, Gonzalez-Aguilar J, Hui L, Gruenberger TM (2006) Characterization of a 3-Phase a.c. Free burning arc plasma. Plasma Sci Technol 8(2):156-163

78. Gonzalez-Aguilar J, Moreno M, Fulcheri L (2007) Carbon nanostructures production by gas-phase plasma processes at atmospheric pressure. J Phys D Appl Phys 40(8):2361-2374

79. Mariotti D, Ostrikov K (2009) Tailoring microplasma nanofabrication: from nanostructures to nanoarchitectures. J Phys D Appl Phys 42:092002

80. Mariotti D, Sankaran RM (2010) Microplasmas for nanomaterials synthesis. J Phys D Appl Phys 43:323001

81. Belmonte T, Arnoult G, Henrion G, Gries T (2011) Nanoscience with non-equilibrium plasmas at atmospheric pressure. J Phys D Appl Phys 44:363001

82. Mariotti D (2008) Nonequilibrium and effect of gas mixtures in an atmospheric microplasma. Appl Phys Lett 92:3-5

83. Kurunczi P, Shah H, Becker K (1999) Hydrogen Lyman- $\alpha$ and Lyman- $\beta$ emissions from high-pressure microhollow cathode discharges in $\mathrm{Ne}-\mathrm{H}_{2}$ mixtures. J Phys B: At Mol Opt Phys 32:L651-L658

84. Kurunczi P, Lopez J, Shah H, Becker K (2001) Excimer formation in high-pressure microhollow cathode discharge plasmas in helium initiated by low-energy electron collisions. Int $\mathrm{J}$ Mass Spectrom 205:277-283

85. Belostotskiy SG, Khandelwal R, Wang Q, Donnelly VM, Economou DJ, Sadeghi N (2008) Measurement of electron temperature and density in an argon microdischarge by laser Thomson scattering. Appl Phys Lett 92:1-4

86. Rajesh R, Kumar BR, Varshney SK, Kumar M, Chavda C, Thakkar A, Patel NC, Kumar A, Team A (2000) Electron temperature measurements by Thomson scattering system. Pramana 55:733-740

87. Frank K, Ernst U, Petzenhauser WH (2001) Proceedings of Record IEEE international conference on the plasma science. Las Vegas, NV, p 381

88. El-Habachi A, Moselhy M, Stark RH, Schoenbach KH (2000) Excimer emission from microhollow cathode discharges. ICOPS 2000 IEEE conference Rec-Abstr 27th IEEE international conference on plasma science (Cat No.00CH37087). doi:10.1109/PLASMA.2000.855103

89. Moselhy M, Shi W, Stark RH, Schoenbach KH (2001) Xenon excimer emission from pulsed microhollow cathode discharges. Appl Phys Lett 79:1240-1242

90. Gill P, Webb CE (2001) Electron energy distributions in the negative glow and their relevance to hollow cathode lasers. J Phys D Appl Phys 10:299-301

91. Iza F, Lee JK, Kong MG (2007) Electron kinetics in radio-frequency atmospheric-pressure microplasmas. Phys Rev Lett 99:2-5

92. Choi J, Iza F, Lee JK, Ryu CM (2007) Electron and ion kinetics in a DC microplasma at atmospheric pressure. IEEE Trans Plasma Sci 35(5):1274-1278

93. Zhu XM, Walsh JL, Chen WC, Pu YK (2012) Measurement of the temporal evolution of electron density in a nanosecond pulsed argon microplasma: using both Stark broadening and an OES line-ratio method. J Phys D Appl Phys 45:295201

94. Zhu XM, Chen WC, Pu YK (2008) Gas temperature, electron density and electron temperature measurement in a microwave excited microplasma. J Phys D Appl Phys 41:105212

95. Iza F, Hopwood JA (2005) Self-organized filaments, striations and other nonuniformities in nonthermal atmospheric microwave excited microdischarges. IEEE Trans Plasma Sci 33(2):306-307

96. McKay K, Iza F, Kong MG (2010) Excitation frequency effects on atmospheric-pressure helium RF microplasmas: plasma density, electron energy and plasma impedance. Eur Phys J D 60:497-503

97. Souza-Corrêa JA, Oliveira C, Gomes MP, Amorim J (2010) Electric and spectroscopic properties of argon-hydrogen RF microplasma jets at atmospheric pressure. J Phys D Appl Phys 43:395203

98. Tachibana K (2006) Current status of microplasma research. IEEJ Trans Electr Electron Eng 1:145-155

99. Shimada M, Tynan GR, Cattolica R (2006) Rotational and translational temperature equilibrium in an inductively coupled plasma. J Vac Sci Technol, A 24(5):1878-1883

100. Bazavan M, Iova I (2008) Temperature determination of a cold N2 discharge plasma by the fit of the experimental spectra with the simulated emission spectra. Rom Rep Phys 60(3):671-678

101. Foest R, Schmidt M, Becker K (2006) Microplasmas, an emerging field of low-temperature plasma science and technology. Int J Mass Spectrom 248:87-102

102. Block R, Toedter O, Schoenbach KH (1999) Proceedings of the 30th AIAA plasma dynamics and lasers conference. Norfolk. Paper no. AIAA-99-3434 
103. Block R, Laroussi M, Leipold F, Schoenbach KH (1999) Proceedings of the 14th international symposium on plasma chemistry. Prague, Czech Republic, p 945

104. Lin PA (2012) Design and fabrication of compositionally and shape controlled metal nanoparticles for semiconductor nanowire growth. Case Western Reserve University, New York

105. Penache C, Miclea M, Demian AB, Hohn O, Schossler S, Jahnke T, Niemax K, Bocking HS (2002) Characterization of a high-pressure microdischarge using diode laser atomic absorption spectroscopy. Plasma Sources Sci Technol 11:476-483

106. Becker K, Koutsospyros A, Yin SM, Christodoulatos C, Abramzon N, Joaquin JC, Marino GB (2005) Environmental and biological applications of microplasmas. Plasma Phys Control Fusion 47:B513B523

107. Seto T, Kwon SB, Hirasawa M, Yabe A (2005) Decomposition of toluene with surface-discharge microplasma device. Jpn J Appl Phys 44:5206-5210

108. Mohamed AAH, Block R, Schoenbach KH (2002) Direct current glow discharges in atmospheric air. IEEE Trans Plasma Sci 30(1):182-183

109. Mizeraczyk J, Hrycak B, Jasinski M (2012) Low-temperature microwave microplasma for bio-decontamination. Przegląd Elektrotechniczny 88(9):238-241

110. Kurunczi P, Martus KE, Becker K (2013) Neon excimer emission from pulsed high-pressure microhollow cathode discharge plasmas. Int J Mass Spectrom 223-224:37-43

111. Masoud N, Martus K, Becker K (2004) Vacuum ultraviolet emissions from a cylindrical dielectric barrier discharge in neon and neon-hydrogen mixtures. Int J Mass Spectrom 233:395-403

112. Moselhy M, Stark RH, Schoenbach KH, Kogelschatz U (2001) Resonant energy transfer from argon dimers to atomic oxygen in microhollow cathode discharges. Appl Phys Lett 78:880-882

113. El-Habachi A, Schoenbach KH (1998) Generation of intense excimer radiation from high-pressure hollow cathode discharges. Appl Phys Lett 73:885-887

114. El-Habachi A, Shi W, Moselhy M, Stark RH, Schoenbach KH (2000) Series operation of direct current xenon chloride excimer sources. J Appl Phys 88(6):3220-3224

115. Sladek REJ, Stoffels E, Walraven R, Tielbeek PJA, Koolhoven RA (2004) Plasma treatment of dental cavities: a feasibility study. IEEE Trans Plasma Sci 32(4):2002-2005

116. Shimizu K, Fukunaga H, Tatematsu S, Blajan M (2012) Atmospheric microplasma application for surface modification of biomaterials. Jpn J Appl Phys 51:11PJ01

117. Blajan M, Umeda A, Shimizu K (2013) Surface treatment of glass by microplasma. IEEE Trans Ind Appl 49(2):714-720

118. Eden JG, Park SJ, Ostrom NP, Chen KF (2005) Recent advances in microcavity plasma devices and arrays: a versatile photonic platform. J Phys D Appl Phys 38:1644-1648

119. Ichiki T, Koidesawa T, Horiike Y (2003) An atmospheric-pressure microplasma jet source for the optical emission spectroscopic analysis of liquid sample. Plasma Sources Sci Technol 12:S16-S20

120. Shimizu K, Fukunaga H, Blajan M (2014) Biomedical applications of atmospheric microplasma. Curr Appl Phys 14:S154-S161

121. Chiang WH, Sakr M, Gao XPA, Sankaran RM (2009) Nanoengineering $\mathrm{Ni}_{\mathrm{x}} \mathrm{Fe}_{1-\mathrm{x}}$ catalysts for gasphase, selective synthesis of semiconducting single-walled carbon nanotubes. ACS Nano 3(12):4023-4032

122. Martin V, Bauville G, Sadeghi N, Puech V (2011) Microplasmas as vacuum ultraviolet source for Clatom density measurements by resonance absorption spectroscopy. J Phys D Appl Phys 44:435203

123. Park JB, Oh JS, Gil E, Kyoung SJ, Kim JS, Yeom GY (2009) Plasma texturing of multicrystalline silicon for solar cell using remote-type pin-to-plate dielectric barrier discharge. J Phys D Appl Phys 42:215201

124. Chiang WH, Richmonds C, Sankaran RM (2010) Continuous-flow, atmospheric-pressure microplasmas: a versatile source for metal nanoparticle synthesis in the gas or liquid phase. Plasma Sources Sci Technol 19:034011

125. Becker KH, Schoenbach KH, Eden JG (2006) Microplasmas and applications. J Phys D Appl Phys 39:R55-R70

126. Shimizu Y, Sasaki T, Chandra Bose A, Terashima K, Koshizaki N (2006) Development of wire spraying for direct micro-patterning via an atmospheric-pressure UHF inductively coupled microplasma jet. Surf Coat Technol 200:4251-4256

127. Singh PK, Hopwood J, Sonkusale S (2014) Metamaterials for remote generation of spatially controllable two dimensional array of microplasma. Sci Rep 4:5964

128. Chiang WH, Sankaran RM (2008) Synergistic effects in bimetallic nanoparticles for low temperature carbon nanotube growth. Adv Mater 20:4857-4861

129. Lin PA, Sankaran RM (2011) Plasma-assisted dissociation of organometallic vapors for continuous, gas-phase preparation of multimetallic nanoparticles. Angew Chem Int Ed 50:10953-10956 
130. Kumar A, Ann Lin P, Xue A, Hao B, Khin Yap Y, Sankaran RM (2013) Formation of nanodiamonds at near-ambient conditions via microplasma dissociation of ethanol vapour. Nat Commun 4:2618

131. Shimizu Y, Bose AC, Mariotti D, Sasaki T, Kirihara K, Suzuki T, Terashima K, Koshizaki N (2006) Reactive evaporation of metal wire and microdeposition of metal oxide using atmospheric pressure reactive microplasma jet. Jpn J Appl Phys 45:8228-8234

132. Bose AC, Shimizu Y, Mariotti D, Sasaki T, Terashima K, Koshizaki N (2006) Flow rate effect on the structure and morphology of molybdenum oxide nanoparticles deposited by atmospheric-pressure microplasma processing. Nanotechnology 17:5976-5982

133. Mariotti D, Svrcek V, Kim DG (2007) Self-organized nanostructures on atmospheric microplasma exposed surfaces. Appl Phys Lett 91:2005-2008

134. Mariotti D, Lindstrom H, Bose AC, Ostrikov K (2008) Monoclinic $\beta-\mathrm{MnO}_{3}$ nanosheets produced by atmospheric microplasma: application to lithium-ion batteries. Nanotechnology 19:495302

135. Shimizu Y, Kawaguchi K, Sasaki T, Koshizaki N (2009) Generation of room-temperature atmospheric $\mathrm{H}_{2}$ /Ar microplasma jet driven with pulse-modulated ultrahigh frequency and its application to gold nanoparticle preparation. Appl Phys Lett 94:2007-2010

136. Mariotti D, Bose AC, Ostrikov K (2009) Atmospheric-microplasma-assisted nanofabrication: metal and metal-oxide nanostructures and nanoarchitectures. IEEE Trans Plasma Sci 37(6):1027-1033

137. Kona S, Kim JH, Harnett CK, Sunkara MK (2009) Carbon nanotube growth studies using an atmospheric, microplasma reactor. IEEE Trans Nanotechnol 8(3):286-290

138. Shirai H, Kobayashi T, Hasegawa Y (2005) Synthesis of silicon nanocones using rf microplasma at atmospheric pressure. Appl Phys Lett 87:143112

139. Nozaki T, Sasaki K, Ogino T, Asahi D, Okazaki K (2007) Microplasma synthesis of tunable photoluminescent silicon nanocrystals. Nanotechnology 18:235603

140. Suzuki T, Kato M, Shimizu Y (2013) Fabrication of titanium-based hard coatings by atmospheric microplasma-metal organic chemical vapor deposition using titanium tetraisopropoxide. Int $\mathrm{J}$ Autom Technol 7(6):720-725

141. Yoshiki $\mathrm{H}$, Mitsui $\mathrm{T}$ (2008) $\mathrm{TiO}_{2}$ thin film coating on a capillary inner surface using atmosphericpressure microplasma. Surf Coat Technol 202:5266-5270

142. Koh TL, O’Hara EC, Gordon MJ (2012) Microplasma-based synthesis of vertically aligned metal oxide nanostructures. Nanotechnology 23:425603

143. Yang Z, Shirai H, Kobayashi T, Hasegawa Y (2007) Synthesis of Si nanocones using rf microplasma at atmospheric pressure. Thin Solid Films 515:4153-4158

144. Shimizu Y, Sasaki T, Ito T, Terashima K, Koshizaki N (2003) Fabrication of spherical carbon via UHF inductively coupled microplasma CVD. J Phys D Appl Phys 36:2940-2944

145. Cao Z, Walsh JL, Kong MG (2009) Atmospheric plasma jet array in parallel electric and gas flow fields for three-dimensional surface treatment. Appl Phys Lett 94:021501

146. Li CJ, Sun B (2004) Microstructure and property of $\mathrm{Al}_{2} \mathrm{O}_{3}$ coating microplasma-sprayed using a novel hollow cathode torch. Mater Lett 58:179-183

147. Akolkar R, Sankaran RM (2013) Charge transfer processes at the interface between plasmas and liquids. J Vac Sci Technol, A 31:050811

148. Ghosh S, Bishop B, Morrison I, Akolkar R, Scherson D, Mohan Sankaran R (2015) Generation of a direct-current, atmospheric-pressure microplasma at the surface of a liquid water microjet for continuous plasma-liquid processing. J Vac Sci Technol, A 33:021312

149. Lu Y, Xu SF, Zhong XX, Ostrikov K, Cvelbar U, Mariotti D (2013) Characterization of a DC-driven microplasma between a capillary tube and water surface. Europhys Lett 102:15002

150. Huang XZ, Zhong XX, Lu Y, Li YS, Rider AE, Furman SA, Ostrikov K (2013) Plasmonic Ag nanoparticles via environment-benign atmospheric microplasma electrochemistry. Nanotechnology 24:095604

151. Huang X, Li Y, Zhong X (2014) Effect of experimental conditions on size control of Au nanoparticles synthesized by atmospheric microplasma electrochemistry. Nanoscale Res Lett 9(1):572

152. Wang R, Zuo S, Zhu W, Zhang J, Fang J (2014) Rapid synthesis of aqueous-phase magnetite nanoparticles by atmospheric pressure non-thermal microplasma and their application in magnetic resonance imaging”. Plasma Process Polym 11:448-454

153. Du C, Xiao M (2014) $\mathrm{Cu}_{2} \mathrm{O}$ nanoparticles synthesis by microplasma. Sci Rep 4:7339

154. Hieda J, Saito N, Takai O (2008) Exotic shapes of gold nanoparticles synthesized using plasma in aqueous solution. J Vac Sci Technol, A 26(4):854-856

155. Imasaka K, Kato Y, Suehiro J (2007) Enhancement of microplasma-based water-solubilization of single-walled carbon nanotubes using gas bubbling in water. Nanotechnology 18:335602

156. Hadzifejzovic E, Elahi A, Caruana DJ (2012) Control of oxidation state of copper in flame deposited films. Thin Solid Films 520(16):5254-5259 
157. Cserfalvi T, Mezei P (1994) Direct solution analysis by glow discharge: electrolyte-cathode discharge spectrometry. J Anal At Spectrom 9:345-349

158. Lukes P, Appleton AT, Locke BR (2004) Hydrogen peroxide and ozone formation in hybrid gas-liquid electrical discharge reactors. IEEE Trans Ind Appl 40(1):60-67

159. Shahbazali E, Hessel V, Noël T, Wang Q (2014) Metallic nanoparticles made in flow and their catalytic applications in organic synthesis. Nanotechnol Rev 3:65-86

160. Kulbe N, Höfft O, Ulbrich A, Zein El Abedin S, Krischok S, Janek J, Pölleth M, Endres F (2011) Plasma electrochemistry in 1-butyl-3-methylimidazolium dicyanamide: copper nanoparticles from $\mathrm{CuCl}$ and $\mathrm{CuCl}_{2}$. Plasma Process Polym 8:32-37

161. Toriyabe Y, Watanabe S, Yatsu S, Shibayama T, Mizuno T (2007) Controlled formation of metallic nanoballs during plasma electrolysis. Appl Phys Lett 91:041501

162. Tomai T, Katahira K, Kubo H, Shimizu Y, Sasaki T, Koshizaki N, Terashima K (2007) Carbon materials syntheses using dielectric barrier discharge microplasma in supercritical carbon dioxide environments. J Supercrit Fluids 41:404-411

163. Sperling RA, Gil PR, Zhang F, Zanella M, Parak WJ (2008) Biological applications of gold nanoparticles. Chem Soc Rev 37:1896-1908

164. Conde J, Doria G, Baptista P (2012) Noble metal nanoparticles applications in cancer. J Drug Deliv 2012:751075. doi:10.1155/2012/751075

165. Doria G, Conde J, Veigas B, Giestas L, Almeida C, Assunção M, Rosa J, Baptista PV (2012) Noble metal nanoparticles for biosensing applications. Sensors 12:1657-1687

166. Chiang WH, Sankaran RM (2007) Microplasma synthesis of metal nanoparticles for gas-phase studies of catalyzed carbon nanotube growth. Appl Phys Lett 91:121503

167. Chiang WH (2009) Engineering nanocatalysts for selective growth of carbon nanotubes. Case Western Reserve University, USA

168. Askari S, Levchenko I, Ostrikov K, Maguire P, Mariotti D (2014) Crystalline Si nanoparticles below crystallization threshold: effects of collisional heating in non-thermal atmospheric-pressure microplasmas. Appl Phys Lett 104:163103

169. Du B, Mohr S, Luggenhölscher D, Czarnetzki U (2011) An atmospheric pressure self-pulsing micro thin-cathode discharge. J Phys D Appl Phys 44:125204

170. Sankaran RM, Holunga D, Flagan RC, Giapis KP (2005) Synthesis of blue luminescent Si nanoparticles using atmospheric-pressure microdischarges. Nano Lett 5(3):537-541

171. Mangolini L, Thimsen E, Kortshagen U (2005) High-yield plasma synthesis of luminescent silicon nanocrystals. Nano Lett 5(4):655-659

172. Barwe B, Stein A, Cibulka OE, Pelant I, Ghanbaja J, Belmonte T, Benedikt J (2014) Generation of silicon nanostructures by atmospheric microplasma jet: the role of hydrogen admixture. Plasma Process Polym 12(2):132-140

173. Peng KQ, Wang X, Li L, Hu Y, Lee ST (2013) Silicon nanowires for advanced energy conversion and storage. Nano Today 8:75-97

174. Schmidt V, Wittemann JV, Senz S, Gósele U (2009) Silicon nanowires: a review on aspects of their growth and their electrical properties. Adv Mater 21:2681-2702

175. Hasan M, Huq MF, Mahmood ZH (2013) A review on electronic and optical properties of silicon nanowire and its different growth techniques. Springerplus 2(1):151

176. Garnett E, Yang P (2010) Light trapping in silicon nanowire solar cells. Nano Lett 10(3):1082-1087

177. Bogart TD, Oka D, Lu X, Gu M, Wang C, Korgel BA (2014) Lithium ion battery performance of silicon nanowires with carbon skin. ACS Nano 8(1):915-922

178. Chen KI, Li BR, Chen YT (2011) Silicon nanowire field-effect transistor-based biosensors for biomedical diagnosis and cellular recording investigation. Nano Today 6(2):131-154

179. Barborini E, Ducati C, Leccardi M, Bertolini G, Repetto P, Milani P (2011) Nanostructured refractory metal oxide films produced by a pulsed microplasma cluster source as active layers in microfabricated gas sensors. Jpn J Appl Phys 50:01AK01

180. Li Y, Della Valle F, Simonnet M, Yamada I, Delaunay JJ (2009) High-performance UV detector made of ultra-long $\mathrm{ZnO}$ bridging nanowires. Nanotechnology 20:045501

181. Liu G, Gao J, Ai H, Chen X (2013) Applications and potential toxicity of magnetic iron oxide nanoparticles. Small 9(9):1533-1545

182. Iida C, Sato M, Nakayama M, Sanada A (2011) Electrodeposition of $\mathrm{Cu}_{2} \mathrm{O}$ nanopyramids using an anodic aluminum oxide template. Int J Electrochem Sci 6:4730-4736

183. Tiwari DK, Behari J, Sen P (2008) Application of nanoparticles in waste water treatment. Carbon Nanotube 3(3):417-433

184. Hashimoto $\mathrm{K}$, Irie $\mathrm{H}$, Fujishima A (2005) $\mathrm{TiO}_{2}$ photocatalysis: a historical overview and future prospects. Jpn J Appl Phys 44(12):8269-8285 
185. Ruppi S (2005) Deposition, microstructure and properties of texture-controlled CVD $\alpha-\mathrm{Al}_{2} \mathrm{O}_{3}$ coatings. Int J Refract Met Hard Mater 23:306-316

186. Eskandari A, Sangpour P, Vaezi MR (2014) Hydrophilic $\mathrm{Cu}_{2} \mathrm{O}$ nanostructured thin films prepared by facile spin coating method: investigation of surface energy and roughness. Mater Chem Phys 147(3):1204-1209

187. Lee YJ, Seo YI, Kim SH, Kim DG, Kim YD (2009) Deposition of Mo oxide and metallic Mo films by chemical vapor transport of $\mathrm{MoO}_{3}(\mathrm{OH})_{2}$. Chem Vap Depos 15:199-203

188. Yoshiki H, Orada T, Hirai K, Hatakeyama R (2006) Growth of vertically aligned carbon nanotube bundles using atmospheric-pressure microplasma. Jpn J Appl Phys 45:9276-9279

189. Sankaran RM, Giapis KP (2002) Hollow cathode sustained plasma microjets: characterization and application to diamond deposition. J Appl Phys 92:2406-2411

190. Zou Q, Wang MZ, Li YG, Zhou LH (2009) Fabrication of carbon nanomaterials using pulse microplasma in SEM. Plasma Dev Oper 17:175-180

191. Levchenko I, Ostrikov K, Mariotti D, Švrček V (2009) Self-organized carbon connections between catalyst particles on a silicon surface exposed to atmospheric-pressure $\mathrm{Ar}+\mathrm{CH}_{4}$ microplasmas. Carbon 47:2379-2390

192. Mochalin VN, Shenderova O, Ho D, Gogotsi Y (2011) The properties and applications of nanodiamonds. Nat Nanotechnol 7(1):11-23

193. Zhang Q, Mochalin VN, Neitzel I, Knoke IY, Han J, Klug CA, Zhou JG, Lelkes PI, Gogotsi Y (2011) Fluorescent PLLA-nanodiamond composites for bone tissue engineering. Biomaterials 32(1):87-94

194. De Volder MFL, Tawfick SH, Baughman RH, Hart AJ (2013) Carbon nanotubes: present and future commercial applications. Science 339:535-539

195. Shin SR, Bae H, Cha JM, Mun JY, Chen YC, Tekin H, Shin H, Farshchi S, Dokmeci MR, Tang S, Khademhosseini A (2012) Carbon nanotube reinforced hybrid microgels as scaffold materials for cell encapsulation. ACS Nano 6(1):362-372

196. Kordás K, Tóth G, Moilanen P, Kumpumäki M, Vähäkangas J, Uusimäki A, Vajtai R, Ajayan PM (2007) Chip cooling with integrated carbon nanotube microfin architectures. Appl Phys Lett 90:5-7

197. Yang Z, Kikuchi T, Hatou Y, Kobayashi T, Shirai H (2005) Carbon microstructures synthesized utilizing the RF microplasma jet at atmospheric pressure. Jpn J Appl Phys 44:4122-4127 